\title{
Context Dependent Auditory Thresholds Determined by Brainstem Audiometry and Prepulse Inhibition in Mongolian Gerbils
}

\author{
Markus Walter", Konstantin Tziridis ${ }^{*}$, Sönke Ahlf, Holger Schulze \\ Experimental Otolaryngology, University of Erlangen-Nuremberg, Erlangen, Germany \\ Email: "holger.schulze@uk-erlangen.de
}

Received October 28, 2011; revised November 30, 2011; accepted December 14, 2011

\begin{abstract}
Information on hearing thresholds is not always reliable as differences in these thresholds have been described even for the same species. This may partially be due to different methods used by different labs. A frequently used approach to obtain an estimate of hearing threshold is the electrophysiological recording of auditory brainstem responses (ABR). They are usually recorded under deep anesthesia and represent the auditory evoked far-field potentials at various levels in the central auditory pathway. Alternatively, several behavioral approaches are employed. These commonly use operant or classical conditioning to determine hearing thresholds. A potential disadvantage of these methods is that any sound conditioning may in principle alter auditory perception and therefore auditory thresholds. To exclude this type of methodological bias a prepulse inhibition (PPI) paradigm can be used where an audiogram can be determined without any kind of pre-training. Here we compare the threshold estimates obtained by two different ABR and PPI measurements where stimuli are presented in different contexts, either randomly or non-randomly, to test for a possible effect of auditory sensitization. In addition we test the effect of a frequency specific acoustic trauma on the audiograms obtained with both methods. In general we find behaviorally determined audiograms to be significantly lower in absolute threshold compared to ABR measurements. Furthermore non-randomized presentation context of the stimuli generally results in audiograms with 10 to $15 \mathrm{~dB}$ lower thresholds than pseudo-randomized presentation. Finally, the amount of threshold loss induced by acoustic trauma is similar for all methods tested.
\end{abstract}

Keywords: Acoustic Trauma; Hearing Thresholds; Auditory Processing; Startle Response

\section{Introduction}

Detailed information about the hearing abilities of animal models is a basic prerequisite in experimental and comparative hearing research. Despite this importance, differing audiograms have been described even in the same species by different labs [1,2] which partially may be due to the different methods used to determine hearing thresholds. For rodents [e.g., 3-5], non-human primates [e.g., 2,6], humans [e.g., 7-9] and many other species one of the most common ways to obtain an estimate of hearing thresholds is the auditory brainstem response (ABR). These electrophysiologically recorded auditory evoked far-field potentials are usually obtained under anesthesia [10-12] but in an awake state in humans [e.g., 13]. It represents the mass auditory response on various levels of the peripheral and central auditory pathway including the cochlear spiral ganglions, the cochlear nucleus, the superior olivary complex, the lateral lemniscus, the infe-

${ }^{*}$ Corresponding authors. rior colliculus and sometimes the medial geniculate body and primary auditory cortex $[14,15]$.

Approaches determining audiograms utilize behavioral methods. Several paradigms have been proposed, including operant [16-22] or classical conditioning $[1,23]$ as well as hearing threshold measurements based on acoustic startle responses (ASR) [24,25]. For such behavioral testing of hearing abilities the animals are awake and usually have to be pre-trained on specific tasks in order to evaluate their perception. As any form of auditory learning in principle may change the naïve hearing characteristics [26-28], a behavioral method that requires no pretraining is favorable. Such method is the prepulse inhibittion (PPI), where the strength of an ASR to an auditory stimulus can gradually be modified by preceding test sounds as a function of the perceptibility of that test sound $[29,30]$ also known as the reflex modification audiometry (RMA) [31-33]. Such behaviorally determined perceptual thresholds reflect neuronal activity within the same neuronal substrate as the ABR measurements, namely the auditory brainstem, and therefore reflect early 
auditory processing in the awake animal.

In order to investigate to what degree the absolute auditory threshold values differ depending on the method used, this study compares audiograms obtained by ABR and PPI measurements. Both methods were carried out with either randomly or non-randomly presented pure tone stimuli representing two different contexts in Mongolian gerbils (Meriones unguiculatus). This approach was used to investigate if auditory sensitization plays a similar role in these brainstem-based methods as in primary auditory cortex [34] or the inferior colliculus [35,36].

We find behavioral audiograms in general being significantly lower in absolute threshold compared to the audiograms determined by ABR. Despite this absolute threshold shift, no differences in the frequency dependent threshold course could be detected between methods. This holds true for audiograms obtained in both normal hearing and hearing impaired animals, that is, before and after induction of a frequency specific acoustic trauma. We also find a clear contextual effect of order of stimulus presentation with the non-randomized paradigms resulting in lower absolute thresholds. Finally, we demonstrate that the magnitude of recovery of hearing thresholds from acoustic trauma can be well described with either method.

\section{Experimental Procedure}

\subsection{Animals and Experimental Groups}

A total of 37 adult male Mongolian gerbils (Meriones unguiculatus) obtained from Charles River (Charles River, Sulzfeld, Germany) were used in this study. All animals were between 3 and 6 month of age with weights ranging from 68 to 95 grams at the date of first testing. All testing was usually carried out within 14 days. The gerbils were housed in a standard animal rack (Bio A. S. Vent Light, Ehret Laborund Pharmatechnik, Emmendingen, Germany) in groups of 2 to 3 animals per cage with free access to water and food at $20^{\circ} \mathrm{C}$ to $24^{\circ} \mathrm{C}$ room temperature. The use and care of animals was approved by the state of Bavaria (Regierungspräsidium Mittelfranken, Ansbach, Germany).

The animals were separated into two major groups: 21 animals received an acoustic trauma (T) and 6 animals served as control group (C). Within group T, 19 animals showed at least $10 \mathrm{~dB}$ acute hearing threshold loss at the trauma frequency measured with ABR (cf. 2.3). In two animals we did not find any trauma induced hearing loss and discarded them from the study. 10 additional animals were used for a rapid stimulation experiment (R) with a different ABR stimulus timing.

Within group T 15 animals (group TP) were tested with non-randomized PPI stimulus sets (cf. below). The remaining 4 animals (group TC) were used for the evaluation of the effect of varying startle stimulus intensities without any pre-stimuli modulating the PPI. All 19 animals of group $\mathrm{T}$ were tested with the pseudo-randomized
ABR stimulus set. The 6 animals in the group $C$ were tested with pseudo-randomized PPI and non-randomized ABR stimulus sets.

\subsection{Acoustic Trauma}

A frequency specific acoustic trauma was induced by free field presentation of a pure tone of $2 \mathrm{kHz}$ with an intensity of $115 \mathrm{~dB}$ SPL (measured in $10 \mathrm{~cm}$ distance from the speaker) for 75 minutes. During presentation of this traumatizing stimulus the animals were placed in an acoustic chamber (Industrial Acoustic Company, Niederkrüchten, Germany), deeply anesthetized with a subcutaneous ketamine-xylacin-anesthesia (mixture of ketamine hydrochloride: 96 mg/kg (Ketamin-ratiopharm, Ratiopharm, Ulm, Germany); xylacin hydrochloride: 4 mg/kg (Rompun 2\%, Bayer, Leverkusen, Germany); atropine sulfate: $1 \mathrm{mg} / \mathrm{kg}$ (Atropinsulfat, B. Braun Melsungen AG, Melsungen, Germany) and physiological NaCl-solution (Berlin-Chemie AG, Berlin, Germany). Ratio: 9:1:2:8). During the procedure anesthesia was maintained by subcutaneous infusion of the anesthetic solution supplied by a syringe pump (WPI SP100IZ, World Precision Instruments, Berlin, Germany) at a rate of 0.2 to $0.3 \mathrm{ml} / \mathrm{h}$. Depth of anesthesia was controlled via video surveillance. Additional doses of the anesthetic solution were applied if necessary.

The traumatizing sound signal was generated by a waveform generator (HP 33120A, Hewlett-Packard, Böblingen, Germany), amplified by a custom-made amplifier (AMP75 wideband power amplifier, Thomas Wulf, Frankfurt, Germany) and presented free-field to both ears by a Canton PlusXS.2 Speaker (Canton Elektronik GmbH, Weilrod, Germany) at a distance of $10 \mathrm{~cm}$ from the animals pinnae. Signal level was controlled using a measuring amplifier (B\&K Type 2610, Bruel and Kjaer, Naerum, Denmark) with a preamplifier/condensor microphone combination (B\&K Type 2669/B\&K Type 4190, Bruel and Kjaer, Naerum, Denmark). For maintenance of the body temperature the anesthetized animals were placed on a regulated warming pad (FHC Inc., Bowdoin, ME, USA). Immediately after the end of the trauma an ABR $\left(A B R_{\text {post }}\right)$ was acquired. Note that the $P P I_{\text {post }}$ was recorded about 4 days after the trauma. We chose this long time after the acoustic trauma to ensure that the animal recovered from the deep anesthesia needed for the trauma and the $\mathrm{ABR}_{\text {post }}$ measurement. In four animals of group TP we exemplarily repeated the measurement of the ABR approximately two weeks (median with upper and lower quartile of 13 days $(10,14.5)$ ) after the acoustic trauma to assess the recovery from the trauma.

\subsection{Auditory Brainstem Responses}

For ABR measurements the gerbils were anesthetized and placed in an acoustic chamber on a regulated warming 
pad as described above for acoustic trauma induction. Silver electrodes for ABR recording were inserted subcutaneously in the infra-auricular region ipsilateral to the sound stimulation side and at the vertex. An additional grounding electrode was placed dorso-sacrally at the back of the animal.

Auditory stimuli were presented free field to one ear at a time with the contralateral ear plugged (Laser lite, Howard Leight Industries, San Diego, CA, USA) and consisted of click or pure tone stimuli with frequencies ranging from 0.5 to $16.0 \mathrm{kHz}$ in half-octave steps. For groups $\mathrm{C}$ and $\mathrm{T}$ the stimuli were always presented in pairs of two with the second stimulus being phase inverted, following after an interstimulus interval of 100 ms. 30 or 60 successive pairs of stimuli were presented at an interval of 500 ms. For group R we used the pseudo-randomized ABR approach (see below) with a stimulation frequency of $26 \mathrm{~Hz}$ in 5 successive blocks of 1 sec each; we used this stimulation frequency to control for repetition rate effects comparable to the experiments performed by Donaldson and Rubel [37].

The stimuli were generated by a custom-made Matlab program (Matlab 2008a, MathWorks Inc., Natick, MA, USA), send out via a NI PCI 6711 card and a BNC2090A breakout box (National Instruments Corporation, Austin, TX, USA), attenuated by a g.pah attenuator (gtec, Graz, Austria) in $5 \mathrm{~dB}$ steps, amplified by a custom-made amplifier and presented via a SinusLive neo 25S speaker (pro hifi, Kaltenkirchen, Germany) at approximately 0.5 $\mathrm{cm}$ distance from the pinna. The output of the speaker was measured prior to the experiment in $0.5 \mathrm{~cm}$ distance by the same preamplifier/condensor microphone combination as described above. The measured frequency transfer function of the speaker was used to calibrate the stimulation software. The duration of the click stimulus was $0.1 \mathrm{~ms}$ while the pure tone stimuli lasted $4 \mathrm{~ms}$ including $1 \mathrm{~ms}$ cosine-squared rise and fall times.

Stimuli were presented either in a pseudo-randomized context using a fixed list of all combinations of stimulus frequencies and sound pressure levels (0 to $90 \mathrm{~dB}$ SPL in $5 \mathrm{~dB}$ steps), randomized across all stimulus set repetitions, or in a non-randomized context where the same stimulus set was presented using a fixed frequency and SPL ordered list. For the latter, stimuli were ordered in frequency specific blocks starting with the click stimulus and then proceeding from lowest to highest stimulus frequency with SPL starting at $0 \mathrm{~dB}$ SPL and increasing in 5 dB steps to $90 \mathrm{~dB}$ SPL.

ABR signals were amplified by a JHM NeuroAmp 401 (Helbig Messtechnik, Mainaschaff, Germany), recorded by a Plexon Multichannel Acquisition Processor (Plexon Inc., Dallas, TX, USA) and saved via a custom-made Matlab program with a sampling rate of $10 \mathrm{kHz}$.

\subsection{Startle and Prepulse Inhibition}

For PPI audiometry/RMA [cf. 33,38,39] awake gerbils were placed in a custom-made acryl tube $10 \mathrm{~cm}$ in front of a speaker in the dark acoustic chamber. The inner diameter of the tube was 40 or $43 \mathrm{~mm}$, depending on the body size of the animal. A grate with a mesh width of 0.5 $\mathrm{mm}$ at the front of the tube prevented the animal from escaping. The combination of tube and mesh did not induce a measurable attenuation of the signal. Frequency distortion never exceeded values of $30 \mathrm{~dB}$ below signal peak amplitude (tested with spectrum analyzer: 3563A Control Systems Analyzer, Hewlett-Packard). The tube was stabilized by foam plastic feet and seated on a piezo sensor (force sensor FSG15N1A, Honeywell, Canada) to register movements of the animal (cf. Figure 1(a)). Surveillance via an infrared video camera (USB mini webcam pro; Lindy-Elektronik GmbH, Mannheim, Germany) ensured an adequate position of the animal in the tube.

A habituation period of 15 minutes before measurement was given to allow the gerbil to accustom to the tube. Prior to PPI behavioral audiometry (see below) we determined for each test frequency the intensity at which the animals started to show a startle response. Therefore, presented stimuli consisted of pure tone stimuli with randomized interstimulus intervals $(10+/-2.5 \mathrm{~s})$ and intensities ranging from 40 to $100 \mathrm{~dB}$ SPL. The stimuli were presented in blocks of 15 trials for each frequency and stimulus intensity. As it turned out, an intensity of 90 dB SPL reproducibly evoked a PPI at all test frequencies (“startle stimulus”).

The stimulus sets used for PPI behavioral audiometry consisted of $90 \mathrm{~dB}$ SPL pure tones with frequencies ranging from 0.5 to $16.0 \mathrm{kHz}$ in one octave steps with prestimuli of the same frequency ranging from 0 to $70 \mathrm{~dB}$ SPL in $10 \mathrm{~dB}$ steps preceding the startle stimulus by 100 ms. The stimuli were either presented in pseudo-randomized or non-randomized attenuation contexts. All stimuli were produced by a custom-made Matlab program, send out via a NI PCI 6229 card and a BNC-2110 breakout box, amplified by a custom-made amplifier and presented by a Canton PlusXS.2 Speaker (corrected for its frequency response function). The interstimulus interval was set to a randomized duration $(10+/-2.5 \mathrm{~s})$. Each pure tone stimulus lasted $6 \mathrm{~ms}$ including $2 \mathrm{~ms}$ cosinesquared rise and fall ramps. For one PPI measurement, the complete stimulus set was presented 15 times. Behavioral data were recorded at a sample rate of $20 \mathrm{kHz}$ during the whole time of interstimulus interval, stimulus presentation and a time period of $400 \mathrm{~ms}$ after the end of the stimulus via the same BNC 2110 breakout box, NI PCI 6229 card and the custom-made Matlab program used for stimulation. The post trauma data were recorded during a time period of 1 to 7 days (median (interquartile range) of $4(2,5)$ days) after the trauma. 


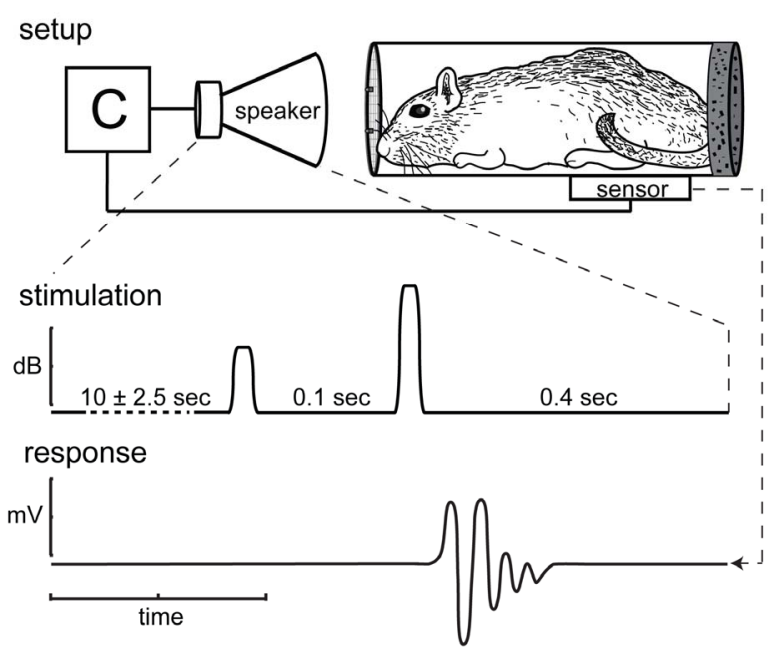

(a)

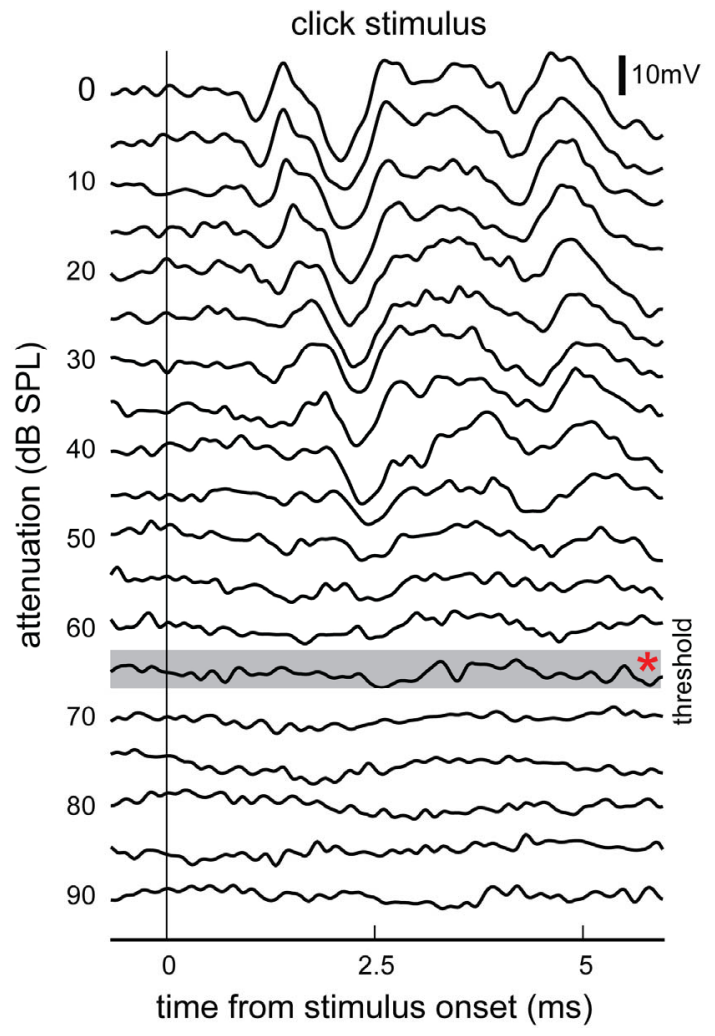

(b)

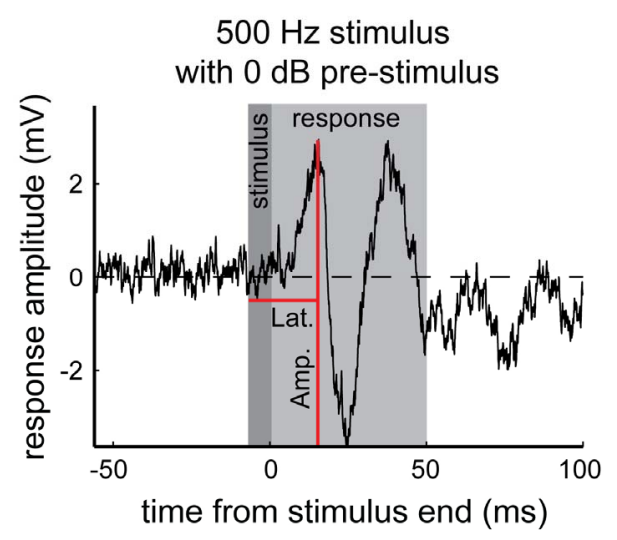

(c)

$500 \mathrm{~Hz}$ stimulus

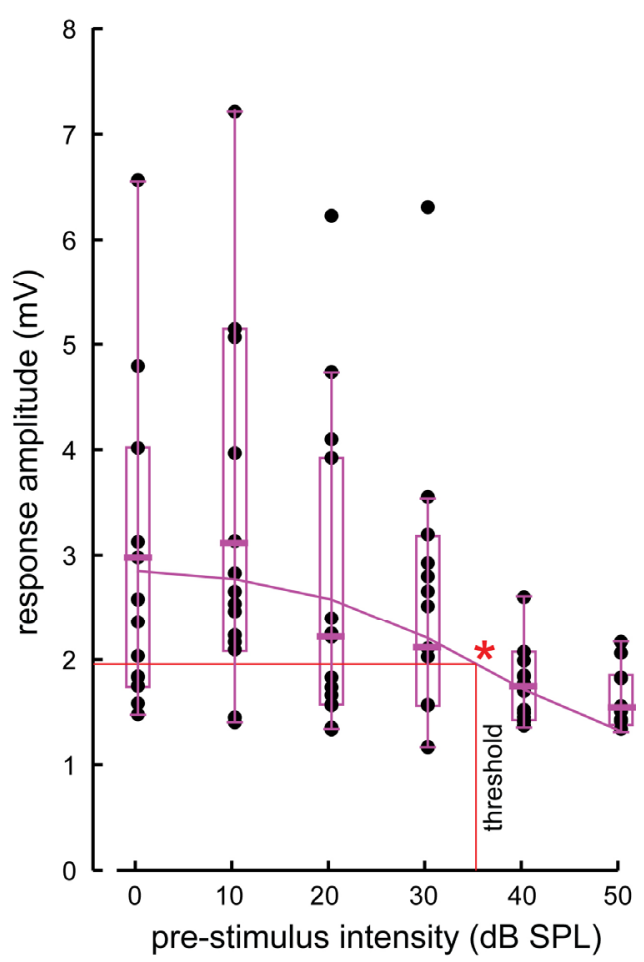

(d)

Figure 1. Startle setup and raw data of both methods used for one exemplary animal to determine hearing thresholds. (a) Schematic drawing of the startle setup. Top: Scheme of the setup with a gerbil in an acryl tube in front of the speaker. Stimulation/recording computer ("C"). Output to the speaker and input from the force piezo sensor ("sensor"). Center: Stimulation timing with pre-stimulus and stimulus (output in dB SPL). Bottom: Response-obtained via the force sensoronly to the stimulus and not to the pre-stimulus; (b) Auditory brainstem response recorded with the "randomized ABR" paradigm and click stimulus presentation. The threshold (red asterisk) is calculated automatically; (c) Startle response for a $500 \mathrm{~Hz}$ stimulus with a pre-stimulus intensity of $0 \mathrm{~dB}$ and a stimulus intensity of $90 \mathrm{~dB}$. The lighter gray area is the time window used for evaluation of the response amplitude (vertical thin red line) and latency (horizontal thin red line). Note that the wave continues with smaller amplitude also after the end of the evaluation window; (d) Raw data (filled circles) of startle response amplitudes (in $\mathrm{mV}$ ) over all pre-stimulus intensities (in dB SPL) at $500 \mathrm{~Hz}$ stimulation frequency; the medians (magenta thick lines), the inter-quartile range (magenta open boxes) and the non-outlier range (magenta error bars) are given). The red asterisk indicates the inflection point at the $\mathbf{5 0 \%}$ level (horizontal red line) of the Boltzmann fit (magenta solid line) that gives the hearing threshold (vertical red line) at this frequency. 


\subsection{Data Analysis}

All data were analyzed with custom-made Matlab programs and statistically evaluated with Statistica 7 (StatSoft, Hamburg, Germany). For each frequency all attenuation ABR waves were plotted and the mean amplitude during a time window of 1 to $5 \mathrm{~ms}$ after the stimulus onset was compared to the mean amplitude before the stimulus (baseline amplitude). The threshold was set at that attenuation where the stimulus amplitude first rose over 2 standard deviations of the baseline amplitude (Figure 1(b)), data of stimuli where this was not possible (approximately 5\%) were discarded. The thresholds obtained for the left and right ear before the trauma were generally not different from each other (in 5/19 (26.3\%) a paired t-test showed a significant difference) while in nearly half of the cases $(8 / 19,42.1 \%)$ after the trauma the paired t-tests showed a difference in the thresholds of both ears (cf. Table 1). On the other hand, the effect was not side specific, as a 2-factorial repeated measurement ANOVA with the predictors "ear" and "trauma status", i.e., before or after trauma, showed no significant interaction of both predictors on the threshold $(\mathrm{F}(1,830)=0.066, \mathrm{p}=0.79)$. In view of this result the average threshold of both ears for each frequency before and after the trauma was calculated. The data of all animals measured with the same ABR paradigm were pooled and evaluated by parametric statistics.

The PPI data were plotted after the end of the experiment for each trial and visually checked: To ensure that the animal was quiet and attentive, trials with movements of the animal within $50 \mathrm{~ms}$ before the startle stimulus were discarded. Valid trials were automatically analyzed by extracting the largest response amplitude and its response latency within the first $50 \mathrm{~ms}$ after startle stimulus onset (Figure 1(c)). The response amplitudes to the single test/startle stimulus pairs (trials) were further validated by performing non-parametric Kruskal-Wallis-ANOVAs over all trials in each stimulation frequency. Only the data from stimuli in which a significant change of response amplitude over the different pre-stimulus levels was found were used for further analysis (Figure 1(d) exemplary Kruskal-Wallis ANOVA $(\mathrm{H}(5, \mathrm{~N}=76)=$ 39.08, $\mathrm{p}<0.001$ ). These data were normalized by dividing the amplitude by the median amplitude of the lowest pre-stimulus intensity (0 dB SPL) and multiplied it with 100 for pre- and post-trauma (conditions) separately to minimize the variance of the response amplitude and prevent any effect of possible interactions between the different frequencies and recording days, the resulting value is called "prepulse inhibition (\%)". Furthermore the Kolmogorov-Smirnov test now did not reject normal distribution ( $\mathrm{p}>0.1$ ) which allowed us to perform parametric statistics (single and two sample t-tests and ANOVA with Scheffe posthoc tests). Boltzmann-functions were
Table 1. Results of t-tests between both ears of $\mathbf{T}$ group animals.

\begin{tabular}{|c|c|c|c|c|c|c|c|}
\hline \multirow[b]{2}{*}{ animal } & \multirow[b]{2}{*}{ ear } & \multicolumn{3}{|c|}{ pre trauma } & \multicolumn{3}{|c|}{ post trauma } \\
\hline & & $\begin{array}{c}\text { mean } \\
\text { threshold }\end{array}$ & SD & p-value & $\begin{array}{c}\text { mean } \\
\text { threshold }\end{array}$ & SD & p-value \\
\hline \multirow{2}{*}{ MW01 } & 1 & 46.3 & 12.8 & \multirow{2}{*}{0.93} & 64.5 & 6.9 & \multirow{2}{*}{0.89} \\
\hline & $\mathrm{r}$ & 45.8 & 11.4 & & 65.0 & 5.5 & \\
\hline \multirow{2}{*}{ MW02 } & 1 & 47.5 & 9.9 & \multirow{2}{*}{0.87} & 60.5 & 11.1 & \multirow{2}{*}{0.21} \\
\hline & $\mathrm{r}$ & 46.7 & 11.5 & & 66.4 & 6.7 & \\
\hline \multirow{2}{*}{ MW03 } & 1 & 49.0 & 8.2 & \multirow{2}{*}{1.00} & 50.8 & 15.6 & \multirow{2}{*}{0.007} \\
\hline & $\mathrm{r}$ & 49.0 & 10.8 & & 60.8 & 11.2 & \\
\hline \multirow{2}{*}{ MW05 } & 1 & 43.0 & 10.4 & \multirow{2}{*}{0.14} & 65.0 & 6.4 & \multirow{2}{*}{0.031} \\
\hline & $\mathrm{r}$ & 57.0 & 7.6 & & 58.3 & 7.2 & \\
\hline \multirow{2}{*}{ MW07 } & 1 & 58.3 & 10.1 & \multirow{2}{*}{0.06} & 59.2 & 9.7 & \multirow{2}{*}{0.60} \\
\hline & $r$ & 51.2 & 7.8 & & 57.5 & 4.5 & \\
\hline \multirow{2}{*}{ MW09 } & 1 & 42.9 & 8.1 & \multirow{2}{*}{0.12} & 53.3 & 6.2 & \multirow{2}{*}{0.001} \\
\hline & $\mathrm{r}$ & 50.8 & 9.7 & & 65.4 & 6.9 & \\
\hline \multirow{2}{*}{ MW13 } & 1 & 52.1 & 7.8 & \multirow{2}{*}{0.09} & 54.1 & 10.0 & \multirow{2}{*}{0.89} \\
\hline & $r$ & 45.0 & 8.8 & & 54.5 & 8.2 & \\
\hline & 1 & 57.1 & 13.4 & & 52.3 & 10.1 & \\
\hline NIVII & $r$ & 46.7 & 9.1 & 0.011 & 56.4 & 10.7 & 0.45 \\
\hline MUT15 & 1 & 59.6 & 5.4 & 0010 & 50.0 & 9.8 & $0000 C_{-1}$ \\
\hline HVIVIJ & $r$ & 50.0 & 10.2 & 0.010 & 59.6 & 6.6 & 0.000 \\
\hline & 1 & 46.3 & 8.8 & & 60.8 & 3.6 & \\
\hline Hover & $\mathrm{r}$ & 51.7 & 8.9 & 0.10 & 68.3 & 8.1 & 0.000 \\
\hline MW10 & 1 & 51.7 & 7.5 & 070 & 65.0 & 8.3 & 0016 \\
\hline S & $\mathrm{r}$ & 53.3 & 11.5 & 0.10 & 55.0 & 8.0 & 0.010 \\
\hline MUW 1 & 1 & 47.1 & 13.7 & 024 & 59.2 & 7.6 & 0000 \\
\hline 101021 & $\mathrm{r}$ & 52.5 & 9.9 & $0.2-7$ & 51.3 & 9.1 & 0.020 \\
\hline & 1 & 50.0 & 11.9 & $0 \in \theta_{-1}>$ & 52.1 & 11.0 & 0 \\
\hline $10 \mathrm{~W} 22$ & $\mathrm{r}$ & 52.1 & 11.6 & 0.00 & 56.7 & 8.9 & 0.20 \\
\hline MUW?2 & 1 & 40.0 & 14.9 & 044 & 58.8 & 7.7 & $0>0$ \\
\hline MVIVLS & $\mathrm{r}$ & 45.4 & 12.7 & 0.44 & 55.0 & 9.0 & $0.2 J$ \\
\hline$M$ & 1 & 48.8 & 8.3 & $050-1$ & 51.7 & 10.1 & 0 \\
\hline & $r$ & 51.3 & 12.5 & & 55.8 & 7.6 & \\
\hline MUT27 & 1 & 45.4 & 9.9 & & 48.3 & 13.2 & 016 \\
\hline miver & $r$ & 47.9 & 10.8 & 0.02 & 56.3 & 7.1 & 0.10 \\
\hline 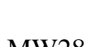 & l & 40.4 & 7.8 & 0001 & 51.7 & 8.6 & 2 \\
\hline IVIVI & $r$ & 49.6 & 5.4 & 0.001 & 54.2 & 6.3 & 0.45 \\
\hline MW & 1 & 58.3 & 6.9 & בחח९ח 0 & 53.3 & 8.8 & 0010 \\
\hline $101 W \angle 9$ & $r$ & 40.4 & 7.5 & 0.00003 & 38.3 & 2.6 & 0.014 \\
\hline & l & 58.3 & 9.6 & & - & - & \\
\hline IVIV & $r$ & 40.0 & 10.7 & 0.0005 & 60.0 & 8.8 & \\
\hline
\end{tabular}


fitted frequency and condition specific to the pooled data of all animals [cf. 32,40] (Equation (1)):

$$
f(x)=a+\frac{b}{1+e^{\frac{x-m}{s}}}
$$

Here a gives the minimum and $\mathrm{b}$ the maximum of the fit. $\mathrm{m}$ is the point of inflection and the $50 \%$ level of the function and $s$ is the slope at the point of inflection. The hearing threshold was defined as the 50\% level of these functions (compare also Figure 3(b)). Response latencythe time from stimulus onset to the first peak of the response-was assessed by non-parametric statistics (e.g., MannWhitney U-tests) as the Kolmogorov-Smirnov test rejected normal distribution ( $\mathrm{p}<0.01)$.

The comparison between the thresholds obtained by ABR and PPI as well as the comparison of thresholds before and after acoustic trauma was performed by single sample t-tests. The analysis of the differences between the different stimulation paradigms was performed with general linear model statistics. Where needed the statistics were Bonferroni corrected to adjust for multiple comparisons.

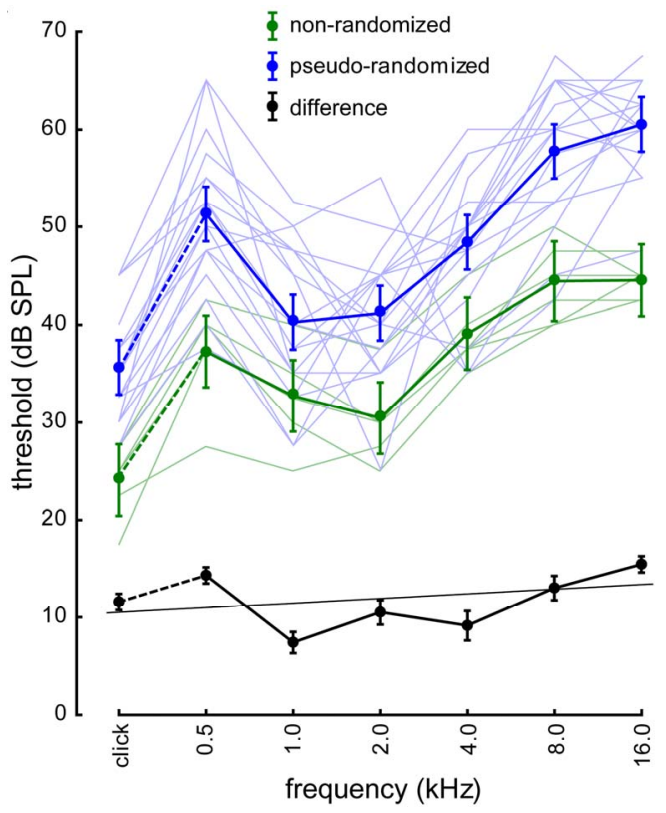

(a)

\section{Results}

\subsection{Context Dependency in Auditory Brainstem Response Audiograms}

The typical approach of ABR measurements in rodents uses between 250 and 2000 pairs of stimuli per frequency and attenuation. We restrained our measurements to 60 pairs of stimuli. In Figure 2(a) the comparison between non-randomized (6 animals, group $\mathrm{C}$ ) and pseudo-randomized (19 animals, group T) ABR measurements is given. A two factorial ANOVA showed a significant effect on the threshold obtained dependent of the context an ABR is measured in $(F(1,194)=174.39, \mathrm{p}<0.001)$ : The mean threshold of the non-randomized ABR (green) across all frequencies was $35.8 \pm 8.3 \mathrm{~dB}$ while the respective thresholds of the pseudo-randomized ABR (blue) averaged to $47.8 \pm 10.9 \mathrm{~dB}$. This shift in threshold did not differ as a function of sound frequency but rather was a parallel shift of the whole audiogram (interaction of ABR type and frequency in the two factorial ANOVA, $F(6,194)=1.52$, $\mathrm{p}=0.17$ ) with a grand-mean of $11.8 \pm 2.9 \mathrm{~dB}$. This fact indicates a considerable dependency of the absolute threshold level on the paradigm, i.e., the stimulus context used.

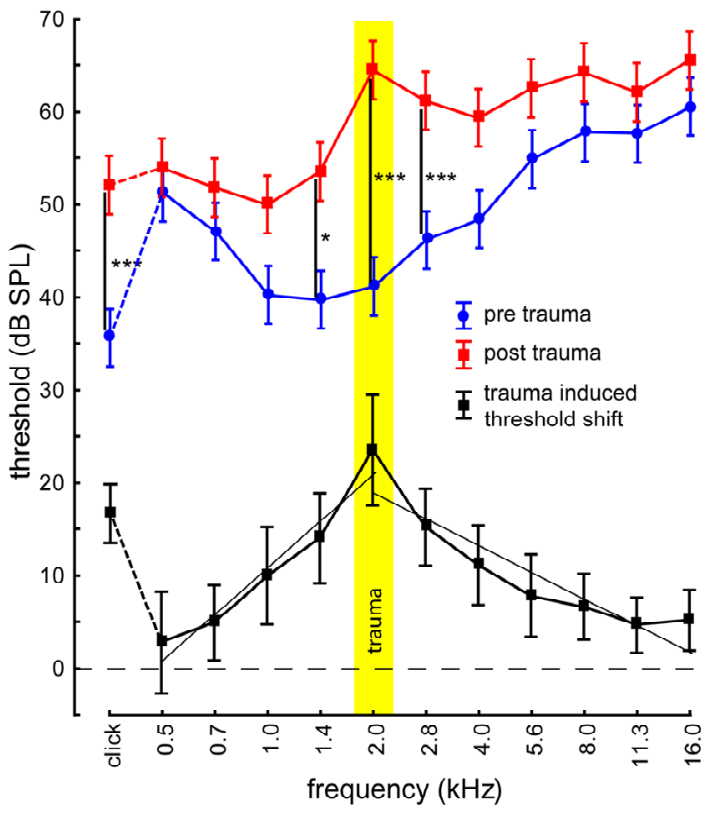

(b)

Figure 2. ABR thresholds. (a) Comparison of non-randomized (green, $n=6)$ and pseudo-randomized $A B R(b l u e, ~ n=19)$ in normal hearing animals. The thick colored lines and symbols give the mean ABR thresholds; the thin colored lines indicate the individual thresholds of the single animals. The black thick line and symbols indicate the difference between the two ABR paradigms; the thin black line represents the linear regression of this difference data. Error bars give the $95 \%$ confidence intervals. Thick broken lines connect the data points obtained with the click measurements with the recordings of the tone stimuli; (b) Trauma effect on the pseudo-randomized ABR threshold. Thresholds before the acoustic trauma (trauma frequency $2000 \mathrm{~Hz}$; yellow area) are given in blue, after the trauma in red $(n=19)$. The trauma induced mean absolute threshold increase is depicted in black. Error bars give the $95 \%$ confidence interval. The thin black lines give the linear regressions to the absolute threshold increase with $r^{2}=0.31, p<0.001$ for frequencies below and $r^{2}=0.29, p<0.001$ for frequencies above the acoustic trauma, respectively. Asterisks give the significant trauma-induced threshold shifts (Scheffe posthoc tests: ${ }^{*} p<$ $0.05,{ }^{* * *}$ p $\left.<0.001\right)$. 


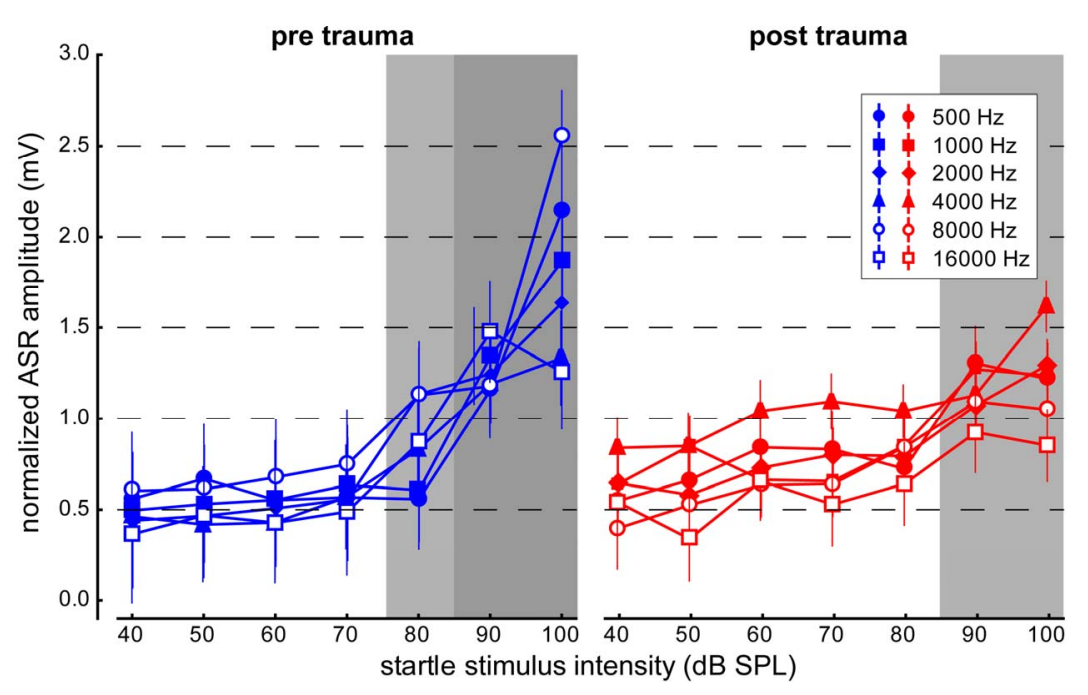

(a)

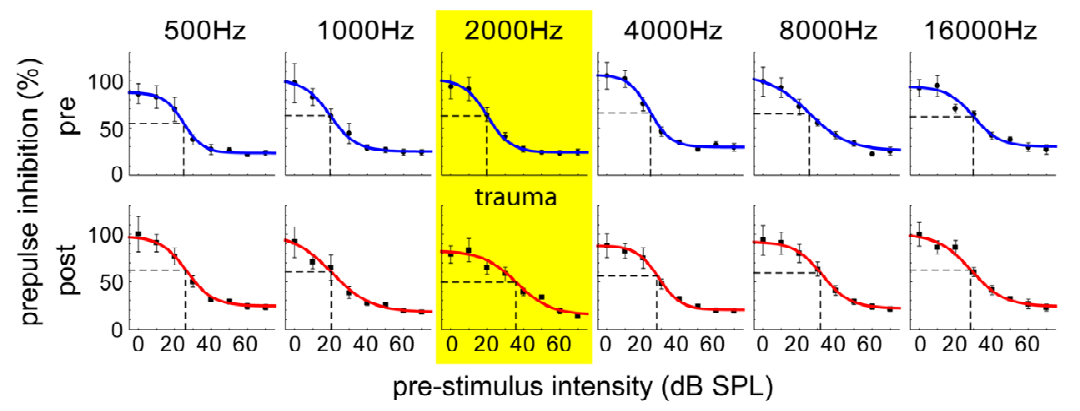

(b)

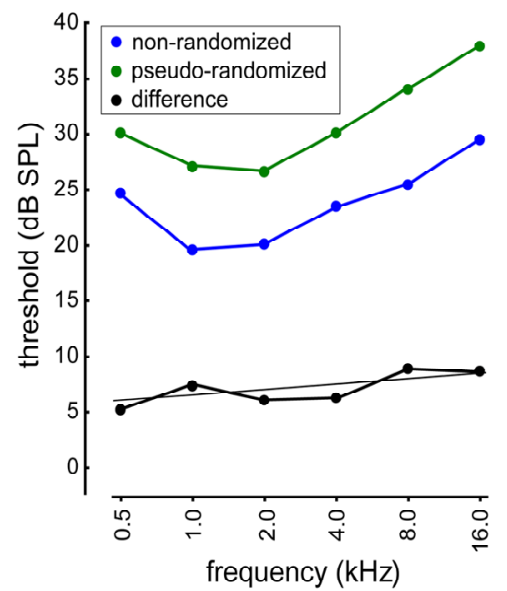

(c)

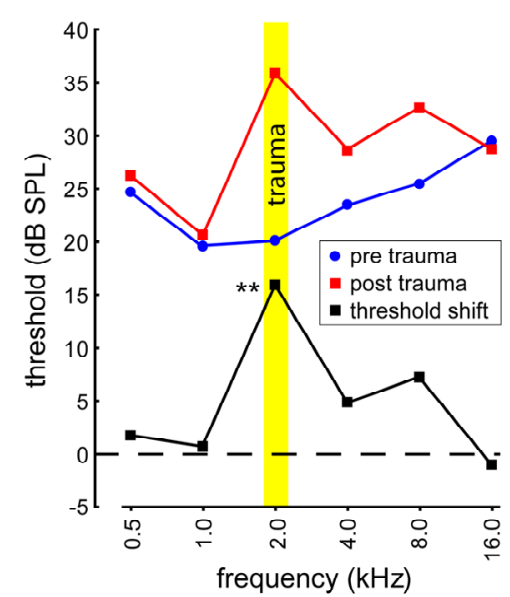

(d)

Figure 3. Startle and PPI thresholds. (a) Normalized ASR amplitude as a function of startle stimulus intensity $(n=4)$. The left panel gives the responses to the different stimulation frequencies before, the right panel after the acoustic trauma. Light gray areas indicate the stimulus intensities where 5 out of 6 posthoc comparisons showed startle responses significantly above baseline, darker grey areas give the intensity where all 6 comparisons became significant. Error bars give the $95 \%$ confidence interval; (b) Boltzmann fits to the pooled data of the non-randomized PPI paradigm (means with standard deviation given as black symbols, $n=15$ ) before (upper panels) and after the trauma (lower panels). The broken horizontal line marks the $50 \%$ level of the fit, the broken vertical line the hearing threshold at this level; (c) Comparison between PPI thresholds with non-randomized (blue, $n=15$ ) and pseudo-randomized stimulus presentation (green, $n=6$ ), with the difference given as thick black symbols and its linear regression as thin black line; (d) PPI thresholds before (blue) and after the trauma (red) computed from the Boltzmann fits in (B). The black line indicates the trauma induced mean absolute threshold shift. Asterisks indicate frequencies with threshold shifts different from all others (single sample t-tests, corrected for multiple comparisons, ${ }^{* *}$ p $\left.<0.01\right)$. 
This interpretation is supported by the lack of a significant slope $(p=0.12)$ of the significant multiple linear regression ( $r=0.64 ; p=0.03$ ) on the difference between the two ABR types (Figure 2(a), black line and symbols). The results of the rapid stimulation experiment (pseudo-randomized ABR with a stimulation frequency of $26 \mathrm{~Hz}$ in 5 successive blocks of $1 \mathrm{sec}$ each) of the 10 animals of group $\mathrm{R}$ generally resulted in even higher thresholds than the pseudo-randomized ABR (data not shown in the figure). Here the mean over all frequencies was $58.6 \pm 9.5$ $\mathrm{dB}$ which is significantly higher than the means of both other paradigms (factor "paradigm" in the two factorial ANOVA: $F(2,257)=217.5, \mathrm{p}<0.001$; Scheffe Posthoc tests: "rapid" vs. "non-randomized" and "rapid" vs. "pseudo-randomized" $\mathrm{p}<0.001$ each). Again the audiogram was shifted in parallel to the audiograms obtained with the two other paradigms, as the interaction of the two factorial ANOVA was not significant $(F(12,257)=1.18$, $\mathrm{p}=0.30$ ).

\subsection{Effect of Acoustic Trauma on Auditory Brainstem Response Audiometry}

To evaluate the extend of a frequency specific acoustic trauma $(2 \mathrm{kHz})$ we used an ABR measurement with the approach of pseudo-randomized stimulus level presentation with usually 60 stimulus pairs per attenuation and frequency. After acquiring the hearing thresholds of the healthy animals, hearing was impaired by an acoustic trauma. The $\mathrm{ABR}_{\text {post }}$ was obtained immediately after the end of the trauma induction procedure. The difference between the baseline audiogram and the acute post trauma threshold of the 19 animals of group $\mathrm{T}$ is shown in Figure 2(b). A two-factorial ANOVA showed a significant difference between the pre trauma and post trauma ABR audiogram over all frequencies $(F(1,432)=238.72, p<0.001)$ with a pre trauma mean of $48.3 \pm 10.3 \mathrm{~dB}$ and a post trauma mean of $58.3 \pm 8.6 \mathrm{~dB}$. The interaction of stimulation frequency and time of measurement (conditions pre trauma and post trauma) also showed a significant effect $(\mathrm{F}(11$, $432)=7.47, \mathrm{p}<0.001)$, indicating that not all frequentcies were significantly affected equally by the trauma. This effect was further investigated by Scheffe posthoc tests that indicated a significant difference in the thresholds at the click stimulus (mean $\mathrm{ABR}_{\mathrm{pre}}: 35.6 \pm 5.9 \mathrm{~dB}$, mean $\mathrm{ABR}_{\text {post }}: 52.1 \pm 6.0 \mathrm{~dB}, \mathrm{p}<0.001$ ), at the $1414 \mathrm{~Hz}$ stimulus (mean $\mathrm{ABR}_{\text {pre: }} 39.7 \pm 6.3 \mathrm{~dB}$, mean $\mathrm{ABR}_{\text {post: }}$ : $53.5 \pm 8.4 \mathrm{~dB}, \mathrm{p}=0.03$ ), at the $2000 \mathrm{~Hz}$ stimulus (mean $\mathrm{ABR}_{\text {pre }}: 41.1 \pm 6.8 \mathrm{~dB}$, mean $\mathrm{ABR}_{\text {post }}: 64.4 \pm 9.1 \mathrm{~dB}, \mathrm{p}<$ 0.001 ) and at the $2828 \mathrm{~Hz}$ stimulus (mean $\mathrm{ABR}_{\text {pre: }} 46.1 \pm$ $6.7 \mathrm{~dB}$, mean $\mathrm{ABR}_{\text {post: }}: 61.1 \pm 6.2 \mathrm{~dB}, \mathrm{p}=0.006$ ). In other words, only thresholds to tone stimuli at or in close spectral vicinity to the traumatizing stimulus and the spectrally broad click stimulus were affected.

The difference between pre and post trauma thresholds- as assessed by the trauma induced mean absolute threshold increase (Figure 2(b), black)—indicated a somewhat broader effect of the acoustic trauma. The single sample students t-tests of the threshold differences against zero (Bonferroni corrected for multiple comparisons) showed significant effects at the click stimulation $(\mathrm{p}<$ $0.001)$ and the stimulation frequencies of $1000 \mathrm{~Hz}(\mathrm{p}=$ 0.01), $1414 \mathrm{~Hz}$ ( $<$ 0.001), $2000 \mathrm{~Hz}(\mathrm{p}<0.001), 2828$ $\mathrm{Hz}(\mathrm{p}<0.001), 4000 \mathrm{~Hz}(\mathrm{p}<0.001), 5656 \mathrm{~Hz}(\mathrm{p}=0.01)$ and $8000 \mathrm{~Hz}(\mathrm{p}=0.01)$. In other words, the acute trauma effect spreads out up to one octave below the trauma frequency and 2 octaves above the trauma frequency. Note that the absolute magnitude of the effect is strongest at the traumatizing frequency and systematically declines as a function of spectral distance of the test frequency to the traumatizing frequency with a slope of $10.06 \mathrm{~dB}$ /octave below and $5.74 \mathrm{~dB} /$ octave above the traumatizing frequency (two linear approximations: $0.5 \mathrm{kHz}$ to $2 \mathrm{kHz}$ and $2 \mathrm{kHz}$ to $16 \mathrm{kHz}$ ).

\subsection{Auditory Startle Response Dependence on Stimulus Intensity}

To assure that the stimulus intensity of the pure tones used for ASR evoked reproducible startle responses at all frequencies we tested different startle stimulus intensities, ranging from 40 to $100 \mathrm{~dB}$ SPL in 4 animals (group TC) before and after induction of an acoustic trauma. We choose this small number of animals, as this experiment was only meant to assure the function of our setup before and after the trauma. Before the trauma the two factorial ANOVA shows a significant increase of normalized response amplitude as a function of stimulus intensity averaged over all frequencies $(F(6,1557)=69.63, p<$ 0.001 ) as well as a significant dependency on the stimulation frequency across all stimulus attenuations $(\mathrm{F}(5$, $1557)=4.05, p=0.001)$. In other words, the normalized response amplitude is dependent on the stimulation frequency and the stimulus intensity. The significant interaction of stimulation frequency and intensity $(\mathrm{F}(30$, $1557)=2.28, p<0.001)$ is depicted on the left side of Figure 3(a) (blue). The white area gives the intensities at which the responses at the different stimulation intensities showed no significant differences between each other in the Scheffe posthoc tests ("baseline" = piezo output without any response to the startle stimulus). The lighter gray area shows the intensity $(80 \mathrm{~dB})$ at which 5 out of the 6 mean responses showed significant differences from the baseline in the Scheffe tests. Finally the darker gray area indicates those stimulus intensities (90 to $100 \mathrm{~dB}$ ) where all 6 responses where significantly different from the baseline and also from each other in the Scheffe tests. Note that also the response at $100 \mathrm{~dB}$ is significantly different from the responses at $90 \mathrm{~dB}$, indicating a further increase in response amplitude at $100 \mathrm{~dB}$ stimulus intensity. 
After the trauma (approximately 4 days) the responses became noisier as can be seen on the right side of Figure 3(a) (red), but overall the normalized response amplitudes at the baseline were not different from before (paired t-test, mean $_{\text {pre }}=0.95 \pm 1.07 \mathrm{mV}$, mean $_{\text {post }}=0.89 \pm 0.53 \mathrm{mV}$, $\mathrm{p}=0.09$ ). The two factorial ANOVA indicated a significant increase over stimulus intensities $(\mathrm{F}(6,1064)=$ $39.06, \mathrm{p}<0.001$ ) as well as a frequency dependency of the mean response $(F(5,1064)=18.97, p<0.001)$. The interaction of stimulus intensity and frequency on the response amplitude (Figure 3(a), right side, red symbols) still was significant $(F(30,1064)=1.50, p=0.03)$, but due to the higher variance at the baseline level, the response amplitude significantly increased only for stimulus intensities of at least $90 \mathrm{~dB}$ ( 5 out of 6 response amplitudes, exception: $16000 \mathrm{~Hz}$, Scheffe posthoc test) and the response did not increase further at $100 \mathrm{~dB}$ (Scheffe posthoc test, $\mathrm{p}=0.43$ ). Comparing the median response latency before and after trauma by Mann-Whitney U-tests for all frequencies resulted in the fact, that only at 4000 $\mathrm{Hz}\left(\mathrm{p}=0.0006\right.$, median $_{\text {pre }}=14.0 \mathrm{~ms}(7.9 \mathrm{~ms}, 19.2 \mathrm{~ms})$, median $_{\text {post }}=16.4 \mathrm{~ms}(10.7 \mathrm{~ms}, 23.0 \mathrm{~ms})$; values in brackets give the lower and upper quartiles) and $8000 \mathrm{~Hz}$ ( $\mathrm{p}=$ 0.01 median $_{\text {pre }}=12.7 \mathrm{~ms}(8.6 \mathrm{~ms}, 19.9 \mathrm{~ms}), \operatorname{median}_{\text {post }}=$ $14.75 \mathrm{~ms}(11.6 \mathrm{~ms}, 26.0 \mathrm{~ms})$ ) a significant increase of latency could be found. Overall the normalized response amplitude seems to be the better predictor of a response in this behavioral paradigm.

\subsection{Context Dependency in Prepulse Inhibition Audiograms}

To obtain audiograms of 15 animals (group TP) with the behavioral measurement of a PPI we used the lowest amplitude of the startle pulse that reliably evoked a response above baseline before and after acoustic trauma which in this case was $90 \mathrm{~dB}$. This startle pulse was preceded by a prepulse with an intensity ranging from 0 to $70 \mathrm{~dB}$ (in ascending order; non-randomized context), where the highest prepulse intensity is below the lowest intensity that induced a significant response above baseline in the control experiment. The normalized response data were pooled and fitted with a sigmoidal function (Boltzmann function, equation 1) as shown in Figure 3(b) all fits were highly significant with $\mathrm{p}<0.001$. The pre-stimulus intensity at the inflection point of the function at $50 \%$ was defined as the hearing threshold at a given frequency before and after trauma.

We additionally tested 6 animals (group C) with a behavioral paradigm that differed in only one major parameter from the preceding method, namely the random order of the pre-stimulus intensity (pseudo-randomized context). We then compared the PPI hearing thresholds of the non-randomized paradigm with the pseudo-randomized pre-stimulus presentation, which is visualized in
Figure 3(c). The difference was calculated and a significant multiple linear regression $(r=0.80, p=0.009)$ with a lack of significant slope $(\mathrm{p}=0.06)$ indicated a similar parallel shift already found in the comparison of the two ABR contexts.

We also compared the response latencies at the different pre-stimulus intensities and frequencies by KruskalWallis ANOVAs. In the animals with the non-randomized stimuli context we found significant effects of the pre-stimulus intensity on the latency in all frequencies (always: $\mathrm{p}<0.001$ ); in other words, no difference between the frequencies was found in the response latency. Multiple comparison of mean ranks showed that the main effect in all frequencies was the significantly higher response latency at a pre-stimulus intensity of $0 \mathrm{~dB}$ compared to higher pre-stimulus intensities usually up to 40 $\mathrm{dB}$. There were no significant differences between the 0 $\mathrm{dB}$ and the 50 to $70 \mathrm{~dB}$ pre-stimulus intensities (median latency (interquartile range)-across all frequencies at pre-stimulus of $0 \mathrm{~dB}$ : $14.4 \mathrm{~ms}(11.5,21.2) ; 10 \mathrm{~dB}: 13.2$ ms (9.75, 21.3); $20 \mathrm{~dB}: 13.0 \mathrm{~ms}(9.5,21.4) ; 30 \mathrm{~dB}: 13.7$ ms (10.4, 22.2); $40 \mathrm{~dB}: 14.5 \mathrm{~ms}$ (10.5, 22.1); $50 \mathrm{~dB}: 15.5$ ms (11.0, 25.6); $60 \mathrm{~dB}: 19.3$ ms (11.8, 27.3); $70 \mathrm{~dB}: 19.8$ ms $(12.9,25.9))$. In the 6 animals of group $C$ tested in the randomized stimuli context the response latency showed a significant increase dependent on the pre-stimulus intensity only at $8000 \mathrm{~Hz}(\mathrm{H}(5, \mathrm{~N}=223)=16.93, \mathrm{p}=0.004)$ with the multiple comparison of mean ranks resulting in only one significant difference at $0 \mathrm{~dB}$ versus $50 \mathrm{~dB}$ prestimulus intensity (median latency at pre-stimulus $0 \mathrm{~dB}$ : $10.6 \mathrm{~ms}(8.0,13.5)$; $50 \mathrm{~dB}$ : $16.6 \mathrm{~ms}(10.1,26.5))$.

\subsection{Effect of Acoustic Trauma on the Prepulse Inhibition Audiometry}

The difference between pre and post trauma response amplitude thresholds is visualized in Figure 3(d). We tested the loss of function $(500 \mathrm{~Hz}: 1.91 \mathrm{~dB}, 1000 \mathrm{~Hz}: 1.15 \mathrm{~dB}$, 2000 Hz: 16.17 dB, 4000 Hz: 4.95 dB, 8000 Hz: 7.32 dB, $16000 \mathrm{~Hz}:-1.17 \mathrm{~dB}$ ) with single sample t-tests compareing each single loss against all others and found only the loss of function at $2000 \mathrm{~Hz}$ to be significant higher (single sample t-test, Bonferroni corrected for multiple comparisons, $\mathrm{p}=0.004$ ).

Investigating the response latency after the acoustic trauma we found that comparisons between pre- and posttrauma latency became highly significant at all tested frequencies (Kruskal-Wallis ANOVA always: $\mathrm{p}<0.001$ ), while the multiple comparisons of ranks now only showed significant differences between the latencies at $0 \mathrm{~dB}$ and usually up to $20 \mathrm{~dB}$ pre-stimulus intensity. Comparing response latencies before and after the trauma we found the median latency became significantly higher after the trauma for all frequencies except $500 \mathrm{~Hz}$ (Mann-Whitney Utests, comparison of latencies before and after trauma, 
$\mathrm{p}$-values between $\mathrm{p}=0.003$ and $\mathrm{p}<0.001$ ). Due to the lack of clearly distinguishable frequency dependent effects of the trauma on response latency, the analysis of the normalized response amplitude again seems to be the better method to obtain the PPI hearing thresholds as we find clear frequency dependent effects there.

\subsection{Comparing ABR and PPI Audiograms}

Figure 4(a) gives an overview of the pre-trauma audiograms obtained with the four different paradigms used in this study. The ABR paradigms generally showed significantly higher thresholds (single sample t-tests, ABR thresholds against PPI threshold, always $\mathrm{p}<0.05$ : green and blue circle symbols) than the respective PPI measurements (green and blue square symbols; also cf. Table 2). The offset between the difference of the two ABR context thresholds (black circles) on the one hand and the difference of the two PPI context thresholds (black squares) on the other hand was generally found to be also sig- nificantly higher (single sample t-tests, mean ABR difference against mean PPI difference: $500 \mathrm{~Hz}: 14.04 \mathrm{~dB}$ vs. $5.53 \mathrm{~dB} ; 1000 \mathrm{~Hz}: 7.53 \mathrm{~dB}$ vs. $7.33 \mathrm{~dB} ; 2000 \mathrm{~Hz}: 10.72$ dB vs. $6.86 \mathrm{~dB} ; 4000 \mathrm{~Hz}: 9.33 \mathrm{~dB}$ vs. $6.84 \mathrm{~dB}$; $8000 \mathrm{~Hz}$ : $13.31 \mathrm{~dB}$ vs. $8.63 \mathrm{~dB} ; 16000 \mathrm{~Hz}: 15.98 \mathrm{~dB}$ vs. $8.08 \mathrm{~dB}$; always $\mathrm{p}<0.05$, except at $1000 \mathrm{~Hz}$, where $\mathrm{p}>0.05$ ). Comparing the two multiple linear regressions of the differences between the pseudo-randomized and non-randomized stimulation contexts in ABR and PPI we found them shifted in parallel (comparison of slopes, $p=0.13$ ). These two results together indicate only a difference in absolute threshold of the two contexts but not in the overall shape of the measured audiogram obtained by the two methods.

When comparing the estimates of hearing loss after acoustic trauma obtained with ABR and PPI measurements, respectively, both methods again yielded comparable results. The two resulting "loss functions" are given in Figure 4(b). We compared each threshold shift at the

Table 2. Mean \pm SD of ABR and PPI thresholds.

\begin{tabular}{|c|c|c|c|c|c|c|c|c|}
\hline \multirow{2}{*}{\multicolumn{2}{|c|}{ Group }} & \multicolumn{7}{|c|}{ Stimulus } \\
\hline & & click & $0.5 \mathrm{kHz}$ & $1 \mathrm{kHz}$ & $2 \mathrm{kHz}$ & $4 \mathrm{kHz}$ & $8 \mathrm{kHz}$ & $16 \mathrm{kHz}$ \\
\hline \multirow{2}{*}{ ABR } & C non-random & $24.09 \pm 4.37 \mathrm{~dB}$ & $37.27 \pm 6.07 \mathrm{~dB}$ & $32.73 \pm 6.07 \mathrm{~dB}$ & $30.45 \pm 4.16 \mathrm{~dB}$ & $39.09 \pm 3.75 \mathrm{~dB}$ & $44.44 \pm 4.64 \mathrm{~dB}$ & $44.55 \pm 4.16 \mathrm{~dB}$ \\
\hline & T pseudo-random & $35.66 \pm 5.94 \mathrm{~dB}$ & $51.32 \pm 7.47 \mathrm{~dB}$ & $40.26 \pm 7.77 \mathrm{~dB}$ & $41.18 \pm 6.84 \mathrm{~dB}$ & $48.42 \pm 7.08 \mathrm{~dB}$ & $57.76 \pm 7.07 \mathrm{~dB}$ & $60.53 \pm 4.90 \mathrm{~dB}$ \\
\hline \multirow{2}{*}{ PPI } & $\mathrm{T}_{\mathrm{P}}$ non-random & - & $24.81 \mathrm{~dB}$ & $19.61 \mathrm{~dB}$ & $20.16 \mathrm{~dB}$ & $23.56 \mathrm{~dB}$ & $25.29 \mathrm{~dB}$ & $29.89 \mathrm{~dB}$ \\
\hline & C pseudo-random & - & $30.28 \mathrm{~dB}$ & $27.02 \mathrm{~dB}$ & $26.82 \mathrm{~dB}$ & $30.28 \mathrm{~dB}$ & $33.83 \mathrm{~dB}$ & $38.03 \mathrm{~dB}$ \\
\hline
\end{tabular}

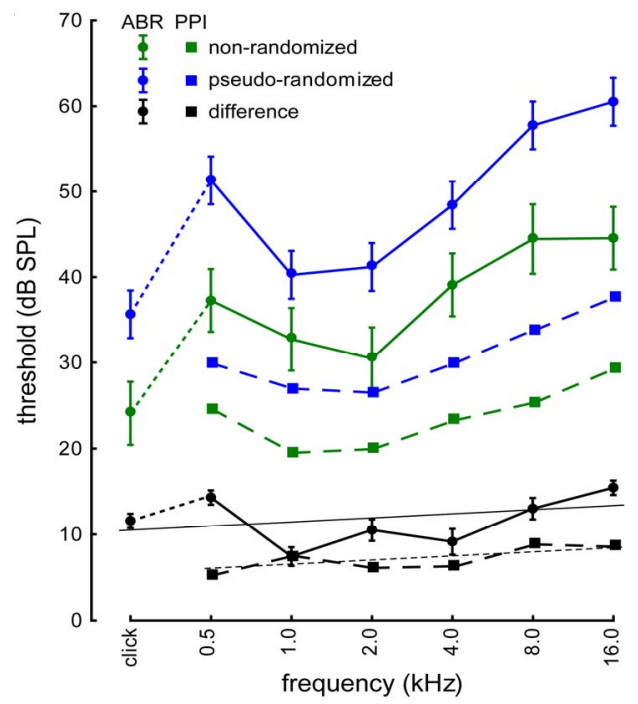

(a)

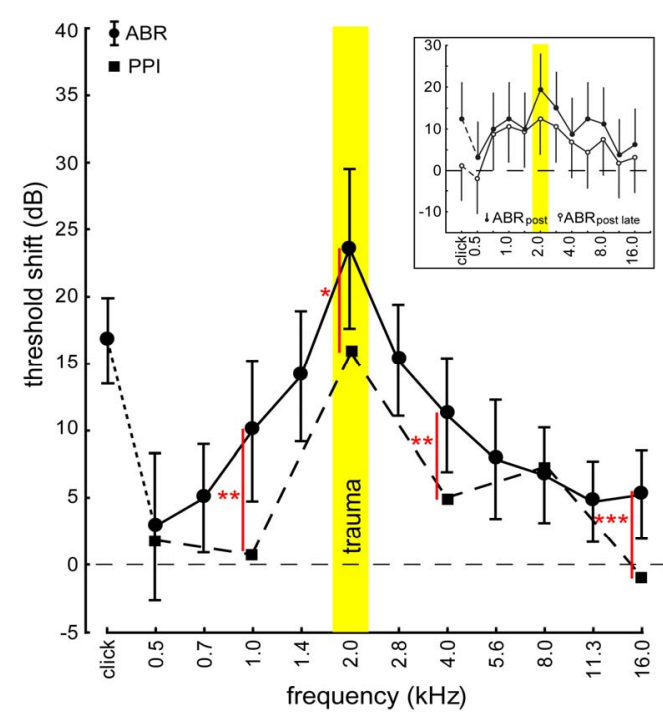

(b)

Figure 4. Comparison of methods and contexts. (a) Overview over the 4 different audiograms. ABR thresholds are indicated by circles, PPI thresholds by squares. Non-randomized contexts are depicted green, pseudo-randomized blue. The difference of the ABR thresholds is indicated as black circles with solid lines and regression, PPI threshold difference is given by black squares with broken lines and regression. Error bars give the $95 \%$ confidence interval; (b) Comparison of the two traumainduced threshold shifts. Circles with error bars $(95 \%$ confidence interval) depict ABR threshold shift $(\mathrm{n}=19)$, squares give behavioral threshold shift $(\mathrm{n}=15)$. Asterisks give the significant single sample t-tests: ${ }^{*} \mathbf{p}<0.05,{ }^{* *} \mathbf{p}<0.01,{ }^{* * *} \mathrm{p}<0.001$. Inset: Comparison the threshold shifts of $\mathbf{A B R}_{\text {post }}$ (filled circles) and $\mathrm{ABR}_{\text {post late }}$ (open circles) of 4 animals. Error bars give the $95 \%$ confidence interval. 
testing frequencies used in both methods by single sample t-tests. In four out of six possible comparisons (single sample t-tests, ABR threshold shift versus PPI threshold shift) the acutely measured ABR threshold loss was significantly larger than the subsequently measured PPI threshold impairment, namely at $1 \mathrm{kHz}(\mathrm{p}=0.002), 2 \mathrm{kHz}(\mathrm{p}=$ $0.02), 4 \mathrm{kHz}(\mathrm{p}=0.008)$ and at $16 \mathrm{kHz}(\mathrm{p}<0.001)$. This change could be interpreted as recovery from the trauma as the hearing loss decreases after the first few days around the trauma frequency significantly. This interpretation is further supported by the change over time found in trauma induced hearing loss assessed by ABR: We exemplarily investigated 4 animals of group TP approximately two weeks (median of 13 days) after the acoustic trauma. The hearing loss at that time was compared with the hearing loss obtained acutely after the acoustic trauma by a two-factorial ANOVA (cf. inset in Figure 4(b)). We found a significant reduction of the auditory impairment over all frequencies in these 4 animals (mean hearing loss acute: $10.41 \pm 9.08 \mathrm{~dB}$, mean hearing loss late: $6.25 \pm 8.26 \mathrm{~dB}, 2$-fact. ANOVA, $\mathrm{F}(1,72)=$ 5.6771, $\mathrm{p}=0.019$ ). The threshold shift-averaged over both time points - showed a significant dependency on the stimulation frequency (2-fact. ANOVA, $\mathrm{F}(11,72)=$ $1.9612, \mathrm{p}=0.045$ ) indicating a chronic impairment centered on the trauma frequency (single sample t-tests vs. 0 : significant hearing loss ranging from $0.7 \mathrm{kHz}$ to $8 \mathrm{kHz}$ with $\mathrm{p}<0.05)$. The interaction of both factors was not significant (2-fact. ANOVA, $\mathrm{F}(11,72)=0.27740, \mathrm{p}=$ 0.98 ) indicating again a parallel shift of the whole audiogram measured at this recovered state of the animals.

\section{Discussion}

With this study we aimed to investigate three questions. First, to which degree the absolute hearing threshold depends on the method used to measure it. Second, if the hearing loss after an acoustic trauma is comparable between two different methods of audiogram determination; and third, if the effect of auditory sensitization dependent on the stimulus context reported in auditory cortex and inferior colliculus is also present in brainstem based electrophysiological and behavioral threshold measurements in rodents. To this mean we investigated audiograms obtained using two different paradigms of ABR and PPI, respectively. A direct comparison within both methods showed that the paradigms with the context of randomized presentation of stimulus intensity always yielded significantly higher thresholds than the paradigms with intensities presented in non-randomized context. These shifts of hearing thresholds were similar for all frequentcies, resulting in parallel shifts of the whole audiogram. Comparing the two different methods we found signifycantly higher thresholds in ABR than in PPI recordings.
The threshold shifts after the frequency specific acoustic trauma were larger in the acutely measured electrophysiological recordings than in the PPIs acquired-averaged-four days later, indicating a threshold recovery or a different sensitivity for trauma-induced threshold loss of the two methods used.

\subsection{Auditory Brainstem Responses}

Acoustic traumata in rodents have been induced by several different methods being either frequency unspecific $[41,42]$ or frequency specific [3]. Usually the loss in hearing threshold varies from 20 to $40 \mathrm{~dB}$, depending on the method and time of measurement. The pronounced hearing loss at higher frequencies in frequency specific acoustic traumata can be explained by the anatomy of the cochlea and is described in classical literature of acoustic traumata $[43,44]$.

In our study a frequency specific acoustic trauma at 2 $\mathrm{kHz}$ was used and the hearing threshold loss was recorded acutely with ABR and after approximately four days with PPI measurements. ABR recording indicated a shift in hearing threshold at $2 \mathrm{kHz}$ which averages to $23.2 \mathrm{~dB}$ compared to $16.1 \mathrm{~dB}$ in the behavioral measurement. As time usually leads to a threshold recovery of 10 to $20 \mathrm{~dB}$ dependent on the initial loss and measured frequency $[3,45,46]$ we believe that the difference in threshold loss determined with our two methods is rather due to the different times of measurement after acoustic trauma rather than due to different sensitivity of the methods. This view is supported by our control measurements of ABRs approximately 2 weeks after the acoustic trauma, in which the mean hearing threshold shift at $2 \mathrm{kHz}$ only averages to $12.5 \pm 7.9 \mathrm{~dB}$. This loss of function is not significantly different (single mean t-test, $p>0.05$ ) from the behavioral measurement on day 4 after trauma and could indicate, that the behavioral threshold measurement already shows the chronic threshold loss after the acoustic trauma. As we measure ABRs in anesthetized animals, an effect of the used anesthetic cannot completely be ruled out [47]. But especially ketamine shows no effect on electrophysiological determined audiograms [48] while other anesthetics can have an impact on such recordings [49].

ABR measurements have been used in many different mammal species, ranging from mice $[12,50]$ to cetaceans $[21,22]$ and from non-human primates $[2,19]$ to humans [51,52]. To our knowledge hardly any study used a pseudo-randomized order of attenuations for different frequencies. Usually the recordings were performed in blocks of attenuations for sounds of single frequencies with up to 2000 repetitions per block either with ascending [50, $53,54]$ or descending $[2,22,55,56]$ stimulus intensities. Note that ascending stimulus intensities—as used in this 
study-seem to result in slightly higher thresholds than stimuli presented with decreasing intensities (comparison of thresholds from the work of Kurt [50] and Zheng [57]) This block-wise type of measurement probably triggers a summation effect leading to a sensitization of the brainstem neurons $[58,59]$ that may foster the recording of lower thresholds and could explain the threshold differences we found using either pseudo-randomized or non-randomized stimulus presentations with low stimulation rate. On the other hand, stimulation with higher stimulus rates in a randomized paradigm (group $\mathrm{R}$ ) has obviously a different effect towards even higher thresholds and could indicate an auditory adaptation process within the different brainstem nuclei responsible for the ABR waves [60].

Auditory context dependent changes have already been described on the neuronal level in primary auditory cortex $[34,61]$, in the auditory midbrain $[35,36]$ and also in the amygdala [62]. As we do not differentiate between the different peaks of the ABR waves we do not know, if a possible neuronal sensitization is confined to specific nuclei-as for example the inferior colliculus as one of the ABR wave generators [63] — or to the whole network, but the magnitude of the difference in context dependent response points to the latter. The audiometric difference between our two presentation contexts was not frequency specific but a parallel shift of the whole audiogram as indicated by the lack of a significant slope of the linear regression to the audiogram differences. The even higher but also parallel shifted ABR thresholds in the "rapid stimulation experiment” (group R) with a pseudo-randomized context but higher temporal presentation frequency $(26 \mathrm{~Hz}$ ) could also point to a strong adaptation mechanism that reduces the amplitude of ABR responses in this context. This is clearly different from the results reported in the "nonrandomized" context work, where these temporal presentation frequencies do not lead to different ABR thresholds [37] which may be due to a possible neuronal adaptation mechanism, as proposed earlier. This view is supported by reports of increasing ABR thresholds with increasing stimulus repetition rate in human infants [64] and bats [65].

In contrast to other studies using ABR measurements for obtaining audiograms we used relatively low stimulation rates and long inter stimulus intervals between the trials in the randomized and non-randomized stimuli sets. Because of the longer timeframe of measurements we had to reduce the number of stimuli to typically 120 (60 pairs) per attenuation in these two paradigms in order to keep the exposure to the anesthetics as low as possible. For group R a comparable number of 130 (5 times 26) stimuli was used and the thresholds were compared by single sample t-tests with the results taken from the work of Boettcher and colleagues [53]. They showed for all comparable frequencies $(1 \mathrm{kHz}, 2 \mathrm{kHz}, 4 \mathrm{kHz}, 8 \mathrm{kHz}, 16$
$\mathrm{kHz}$ ) significant higher thresholds $(\mathrm{p}<0.001)$ in our measurements. These observed differences may be due to the number of stimuli used which is here relatively low compared to the 250 to 2000 stimulus pairs applied in other studies [20,37,53,66,67]. It is also possible, that our relative conservative method of defining the ABR thresholds - compared to the evaluation of the ABR thresholds by eye-with relying on the signal to noise ratio results in higher absolute values. As this is true for both contexts it would give an absolute offset in our data, but should not affect the relative difference between the paradigms.

\subsection{Prepulse Inhibition}

Comparable results were obtained by the second method utilizing the prepulse inhibition of the ASR [32,33,6870], which is a well investigated method to measure behavioral thresholds in animals [29,71]. Furthermore, the method is independent of any pre-training of the animals, e.g., shuttle box based behavioral experiments [20,72]. Usually, behavioral thresholds are measured with randomized stimulus orders [but compare 73], because the effect of constant repetition of the same stimulus as mostly used in ABR measurements is known to produce neuronal adaptation in the auditory cortex $[74,75]$ which is the relevant brain structure for perception and nonreflexive behavior [e.g., 76]. The obtained thresholds within the classical pre-training dependent behavioral paradigms usually do not differ from each other [17] but may show considerable differences when compared with nonbehavioral methods $[1,77,78]$.

One of our main findings, the context dependent difference found in ABR audiograms, is also present in the behaviorally obtained data. In auditory cortex neuronal adaptation and context dependency have been reported by several groups $[34,61,79]$. Also in the auditory midbrain, an adaptation and context dependent change of neuronal firing rate has been reported [35,36]. As the PPI modulation of the ASR is thought to be independent of the auditory cortex [e.g., 30,80] and context, our data are inconsistent with this view: We do see a different threshold in the two paradigms while the typical parameters of the startle experiments are kept constant. In this study a startle stimulus intensity of $90 \mathrm{~dB}$ SPL was used during PPI modulation which was loud enough to evoke significant responses in all tested frequencies before and after the acoustic trauma. Startle stimuli with a higher intensity resulted in larger response amplitudes (cf. Figure 3(a), left panel) but on the other hand may as well interfere with the much weaker pre-stimulus of the next trial due to the stapedius reflex of the middle ear [81]. On the other hand, the $90 \mathrm{~dB}$ stimulus is relatively low compared to other stimuli reported, which are as loud as 115 
$\mathrm{dB}$ - the sound intensity of the trauma used here. This low intensity could interfere with the dynamic range of the PPI modulation, especially after the trauma. Nevertheless, we do not think this is the case here, as we receive good group fits even after the sound injury of the cochlea.

Pre-stimulus timing does also have an-if not the major-impact on ASR amplitude [29,82], but was not varied in our study. Different pre-stimulus latencies may have an influence on the obtained behavioral thresholds and by this the whole audiogram may be shifted towards or even further away from the ABR audiogram. Other influences are harder to control, e.g., the habituation of the animal itself [71] or different daily amplitudes [83, 84]. We tried to minimize these factors using an unpredictable interstimulus interval with a mean of 10 seconds as well as 5 minute breaks between the different frequency and intensity sessions (in the case of non-randomized context); additionally all data were normalized to specific reference responses. The PPI based audiograms we report here were obtained either by randomized or stepwise increasing intensity of presented pre-stimuli [82] and averaged across animals, because we used only 15 repetitions per pre-stimulus intensity and frequency, which resulted in relative noisy thresholds on the level of the single animal. To obtain individual audiograms more repetitions per stimulus would be needed. Alternatively an adaptive threshold tracking method might allow an even faster threshold determination. In comparison with other studies in rodents the animal numbers used here is relatively small but gerbils are known to show only little variance in the ASR amplitude [85]. The response amplitudes were fitted with sigmoidal functions (Equation (1)), comparable to the ones supposed by Grassi and Soranzo [40] or used by Fechter and colleagues [32], which allows a determination of the hearing thresholds even between the presented intensities. On the other hand, response latencies showed effects already at $10 \mathrm{~dB}$ and may indicate an even lower absolute threshold for the PPI than determined by the response amplitude. But as we were not able to calculate any systematic, statistically significant latency effect across all test frequencies, we focused our analysis on the amplitudes only.

\subsection{Conclusion}

Similar to the electrophysiological ABR recordings, where the randomized paradigm resulted in averaged $11.8 \pm 2.9 \mathrm{~dB}$ higher thresholds than the non-randomized context, we found in the behavioral measurements that the randomized paradigm resulted in higher absolute thresholds of averaged $7.1 \pm 1.1 \mathrm{~dB}$ indicating a context dependency not only for the ABR but also for the reflexive behavior method. Comparing the linear regressions of both methods' threshold shifts we found them to be quantitatively but not qualita- tively different, as the slopes did not differ. The "best" ABR recordings and "worst" PPI audiograms obtained differed by 10 to $15 \mathrm{~dB}$ SPL which is in line with results obtained from rabbits comparing the two methods of audiogram determination [23]. There, the ABR thresholds were found to be 10 to $20 \mathrm{~dB}$ higher than the behaviorally obtained ones (lowest differences at $2 \mathrm{kHz}$, highest at $16 \mathrm{kHz}$ ) but also generally shifted in a parallel manner. So the method of PPI modulated ASR results in comparable thresholds to more demanding and learning intensive paradigms [e.g., 78]. In the ABR recording the context dependency could be explained by the already described neuronal effects in inferior colliculus but the differences in PPI modulation of ASR between both context paradigms could point to a stronger influence of higher auditory areas on the reflexive brainstem behavior as commonly believed.

\section{Acknowledgements}

For assistance in recording, animal handling and animal caretaking we are grateful to J. C. Stepper. This work was supported by the Interdisciplinary Center for Clinical Research (IZKF, project E7) at the University Hospital of the University of Erlangen-Nuremberg.

\section{REFERENCES}

[1] H. Markl and G. Ehret, "Auditory Threshold of the Mouse (Mus musculus). A Critical Evaluation of Methods for Measuring Auditory Threshold in a Mammal," Zeitschrift für Tierpsychologie, Vol. 33, No. 3-4, 1973, pp. 274-286. doi:j.1439-0310.1973.tb02096.x

[2] M. A. Ramsier and N. J. Dominy, “A Comparison of Auditory Brainstem Responses and Behavioral Estimates of Hearing Sensitivity in Lemur catta and Nycticebus coucang," American Journal of Primatology, Vol. 72, No. 3, 2010, pp. 217-233. doi:ajp.20780

[3] H. E. Heffner, G. Koay and R. S. Heffner, “Comparison of Behavioral and Auditory Brainstem Response Measures of Threshold Shift in Rats Exposed to Loud Sound," Journal of the Acoustical Society of America, Vol. 124, No. 2, 2008, pp. 1093-1104. doi:10.1121/1.2949518

[4] K. R. Henry, "Differential Changes of Auditory Nerve and Brain Stem Short Latency Evoked Potentials in the Laboratory Mouse,” Electroencephalography and Clinical Neurophysiology, Vol. 46, No. 4, 1979, pp. 452-459. doi:0013-4694(79)90146-9

[5] S. L. McFadden, E. J. Walsh and J. McGee, "Onset and Development of Auditory Brainstem Responses in the Mongolian Gerbil (Meriones unguiculatus)," Hearing Research, Vol. 100, No. 1-2, 1996, pp. 68-79. doi:0378-5955(96)00108-6

[6] R. E. Lasky, M. M. Maier, E. B. Snodgrass, N. K. Laughlin and K. E. Hecox, "Auditory Evoked Brainstem and Middle Latency Responses in Macaca mulatta and Humans,” Hearing Research, Vol. 89, No. 1-2, 1995, pp. 212- 
225. doi:0378-5955(95)00140-7

[7] A. C. Coats and J. L. Martin, "Human Auditory Nerve Action Potentials and Brain Stem Evoked Responses: Effects of Audiogram Shape and Lesion Location," Archives of Otolaryngology, Vol. 103, No. 10, 1977, pp. 605622.

[8] H. Davis, S. K. Hirsh, L. L. Turpin and M. E. Peacock, "Threshold Sensitivity and Frequency Specificity in Auditory Brainstem Response Audiometry,” Audiology, Vol. 24, No. 1, 1985, pp. 54-70.

[9] B. L. Lonsbury-Martin, F. P. Harris, B. B. Stagner, M. D. Hawkins and G. K. Martin, "Distortion Product Emissions in Humans. I. Basic Properties in Normally Hearing Subjects," The Annals of Otology, Rhinology \& Laryngology, Vol. 147, 1990, pp. 3-14.

[10] S. H. Sha, et al., "Age-Related Auditory Pathology in the CBA/J Mouse,” Hearing Research, Vol. 243, No. 1-2, 2008, pp. 87-94. doi:j.heares.2008.06.001

[11] H. Winter, et al., "Deafness in TRbeta Mutants Is Caused by Malformation of the Tectorial Membrane," Journal of Neuroscience, Vol. 29, No. 8, 2009, pp. 2581-2587. doi:JNEUROSCI.3557-08.2009

[12] X. Zhou, P. H. Jen, K. L. Seburn, W. N. Frankel and Q. Y. Zheng, "Auditory Brainstem Responses in 10 Inbred Strains of Mice,” Brain Research, Vol. 1091, No. 1, 2006, pp. 16-26.

[13] J. W. Hall and D. W. Swanepoel, “Objective Assessment of Hearing,” Plural Publishing, Inc., San Diego, 2010.

[14] K. R. Henry, "Auditory Brainstem Volume-Conducted Responses: Origins in the Laboratory Mouse,” Journal of the American Auditory Society, Vol. 4, No. 5, 1979, pp. 173-178.

[15] B. L. Lonsbury-Martin, G. K. Martin and M. T. Hannley, "Physiology of the Auditory and Vestibular System," In: J. B. Snow and P. A. Wackym, Eds., Ballenger's Otorhinolaryngology: Head and Neck Surgery, 2009.

[16] H. Heffner and B. Masterton, "Hearing in Primitive Primates: Slow Loris (Nycticebus coucang) and Potto (Perodicticus potto)," Journal of Comparative and Physiological Psychology, Vol. 71, No. 2, 1970, pp. 175-182. doi:h0029138

[17] R. S. Heffner and H. E. Heffner, "Behavioral Hearing Range of the Chinchilla," Hearing Research, Vol. 52, No. 1, 1991, pp. 13-16. doi:0378-5955(91)90183-A

[18] L. L. Jackson, R. S. Heffner and H. E. Heffner, "Free-Field Audiogram of the Japanese Macaque (Macaca fuscata)," Journal of the Acoustical Society of America, Vol. 106, No. 5, 1999, pp. 3017-3023. doi:1.428121

[19] R. E. Lasky, A. A. Soto, M. L. Luck and N. K. Laughlin, "Otoacoustic Emission, Evoked Potential, and Behavioral Auditory Thresholds in the Rhesus Monkey (Macaca mulatta)," Hearing Research, Vol. 136, No. 1-2, 1999, pp. 35-43. doi:S0378-5955(99)00100-8

[20] A. Ryan, "Hearing Sensitivity of the Mongolian Gerbil, Meriones unguiculatis," Journal of the Acoustical Society of America, Vol. 59, No. 5, 1976, pp. 1222-1226. doi:1.380961

[21] M. D. Szymanski, et al., "Killer Whale (Orcinus orca)
Hearing: Auditory Brainstem Response and Behavioral Audiograms," Journal of the Acoustical Society of America, Vol. 106, No. 2, 1999, pp. 1134-1141. doi:1.427121

[22] M. M. Yuen, P. E. Nachtigall, M. Breese and A. Y. Supin, "Behavioral and Auditory Evoked Potential Audiograms of a False Killer Whale (Pseudorca crassidens),” Journal of the Acoustical Society of America, Vol. 118, No. 4, 2005, pp. 2688-2695. doi:1.2010350

[23] E. Borg and B. Engstrom, "Hearing Thresholds in the Rabbit. A Behavioral and Electrophysiological Study,” Acta Otolaryngologica, Vol. 95, No. 1-2, 1983, pp. 19-26.

[24] J. R. Ison, P. Agrawal, J. Pak and W. J. Vaughn, “Changes in Temporal Acuity with Age and with Hearing Impairment in the Mouse: A Study of the Acoustic Startle Reflex and Its Inhibition by Brief Decrements in Noise Level," Journal of the Acoustical Society of America, Vol. 104, No. 3, 1998, pp. 1696-1704. doi:1.424382

[25] G. Yang, et al., "Salicylate Induced Tinnitus: Behavioral Measures and Neural Activity in Auditory Cortex of Awake Rats," Hearing Research, Vol. 226, No. 1-2, 2007, pp. 244-253. doi:j.heares.2006.06.013

[26] M. Brown, D. R. Irvine and V. N. Park, "Perceptual Learning on an Auditory Frequency Discrimination Task by Cats: Association with Changes in Primary Auditory Cortex," Cerebral Cortex, Vol. 14, No. 9, 2004, pp. 952-965. doi:bhh056

[27] F. W. Ohl and H. Scheich, "Learning-Induced Plasticity in Animal and Human Auditory Cortex," Current Opinion in Neurobiology, Vol. 15, No. 4, 2005, pp. 470-477. doi:j.conb.2005.07.002

[28] N. M. Weinberger, "Auditory Associative Memory and Representational Plasticity in the Primary Auditory Cortex,” Hearing Research, Vol. 229, No. 1-2, 2007, pp. 5468. doi:j.heares.2007.01.004

[29] M. Koch, “The Neurobiology of Startle,” Progress in Neurobiology, Vol. 59, No. 2, 1999, pp. 107-128. doi:S0301-0082(98)00098-7

[30] J. Larrauri and N. Schmajuk, "Prepulse Inhibition Mechanisms and Cognitive Processes: A Review and Model,” Neurotransmitter Interactions and Cognitive Function, EXS, Vol. 98, 2006, pp. 245-278. doi:978-3-7643-7772-4 12

[31] K. M. Crofton and X. Zhao, "Mid-Frequency Hearing Loss in Rats Following Inhalation Exposure to Trichloroethylene: Evidence from Reflex Modification Audiometry,” Neurotoxicology and Teratology, Vol. 15, No. 6, 1993, pp. 413-423. doi:0892-0362(93)90059-W

[32] L. D. Fechter, L. Sheppard, J. S. Young and S. Zeger, "Sensory Threshold Estimation from a Continuously Graded Response Produced by Reflex Modification Audiometry,” Journal of the Acoustical Society of America, Vol. 84, No. 1, 1988, pp. 179-185. doi:1.396962

[33] J. S. Young and L. D. Fechter, "Reflex Inhibition Procedures for Animal Audiometry: A Technique for Assessing Ototoxicity," Journal of the Acoustical Society of America, Vol. 73, No. 5, 1983, pp. 1686-1693. doi:1.389391

[34] N. Ulanovsky, L. Las, D. Farkas and I. Nelken, "Multiple Time Scales of Adaptation in Auditory Cortex Neurons," The Journal of Neuroscience, Vol. 24, No. 46, 2004, pp. 


\section{0-10453. doi:JNEUROSCI.1905-04.2004}

[35] I. Dean, N. S. Harper and D. McAlpine, "Neural Population Coding of Sound Level Adapts to Stimulus Statistics," Nature Neuroscience, Vol. 8, No. 12, 2005, pp. 1684-1689.

[36] I. Dean, B. L. Robinson, N. S. Harper and D. McAlpine, "Rapid Neural Adaptation to Sound Level Statistics," Journal of Neuroscience, Vol. 28, No. 25, 2008, pp. 64306438. doi:JNEUROSCI.0470-08.2008

[37] G. S. Donaldson and E. W. Rubel, "Effects of Stimulus Repetition Rate on ABR Threshold, Amplitude and Latency in Neonatal and Adult Mongolian Gerbils," Electroencephalography and Clinical Neurophysiology, Vol. 77, No. 6, 1990, pp. 458-470. doi:0168-5597(90)90006-Y

[38] S. Carlson and J. F. Willott, “The Behavioral Salience of Tones as Indicated by Prepulse Inhibition of the Startle Response: Relationship to Hearing Loss and Central Neural Plasticity in C57BL/6J Mice,” Hearing Research, Vol. 99, No. 1-2, 1996, pp. 168-175. doi:S0378-5955(96)00098-6

[39] J. F. Willott, S. Carlson and H. Chen, "Prepulse Inhibition of the Startle Response in Mice: Relationship to Hearing Loss and Auditory System Plasticity,” Behavioral Neuroscience, Vol. 108, No. 4, 1994, pp. 703-713. doi:0735-7044.108.4.703

[40] M. Grassi and A. Soranzo, "MLP: A MATLAB Toolbox for Rapid and Reliable Auditory Threshold Estimation," Behavioral Research Methods, Vol. 41, No. 1, 2009, pp. 20-28. doi:BRM.41.1.20

[41] F. A. Boettcher, "Susceptibility to Acoustic Trauma in Young and Aged Gerbils," Journal of the Acoustical Society of America, Vol. 112, No. 6, 2002, pp. 2948-2955. doi:1.1513364

[42] A. F. Ryan, T. M. Bennett, N. K. Woolf and A. Axelsson, "Protection from Noise-Induced Hearing Loss by Prior Exposure to a Nontraumatic Stimulus: Role of the Middle Ear Muscles,” Hearing Research, Vol. 72, No. 1-2, 1994, pp. 23-28. doi:0378-5955(94)90201-1

[43] K. R. Henry, "Cochlear Damage Resulting from Exposure to Four Different Octave Bands of Noise at Three Ages," Behavioral Neuroscience, Vol. 98, No. 1, 1984, pp. 107117. doi:0735-7044.98.1.107

[44] J. F. Willott and K. R. Henry, “Auditory Evoked Potentials: Developmental Changes of Threshold and Amplitude Following Early Acoustic Trauma," Journal of Comparative and Physiological Psychology, Vol. 86, No. 1, 1974, pp. 17. doi:h0035922

[45] R. P. Hamernik, W. A. Ahroon and J. A. Patterson Jr., "Threshold Recovery Functions Following Impulse Noise Trauma," Journal of the Acoustical Society of America, Vol. 84, No. 3, 1988, pp. 941-950. doi:1.396663

[46] D. Yamashita, S. B. Minami, S. Kanzaki, K. Ogawa and J. M. Miller, "Bcl-2 Genes Regulate Noise-Induced Hearing Loss,” Journal of Neuroscience Research, Vol. 86, No. 4, 2008, pp. 920-928. doi:jnr.21533

[47] S. Kurt, C. K. Moeller, M. Jeschke and H. Schulze, "Differential Effects of Iontophoretic Application of the $\mathrm{GABA}_{\mathrm{A}}$-Antagonists Bicuculline and Gabazine on ToneEvoked Local Field Potentials in Primary Auditory Cortex: Interaction with Ketamine Anesthesia," Brain Re- search, Vol. 1220, 2008, pp. 58-69.

doi:j.brainres.2007.10.023

[48] R. P. Bobbin, J. G. May and R. L. Lemoine, "Effects of Pentobarbital and Ketamine on Brain Stem Auditory Potentials. Latency and Amplitude Intensity Functions after Intraperitoneal Administration," Archives of Otolaryngology, Vol. 105, No. 8, 1979, pp. 467-470.

[49] F. Dodd and R. R. Capranica, “A Comparison of Anesthetic Agents and Their Effects on the Response Properties of the Peripheral Auditory System," Hearing Research, Vol. 62, No. 2, 1992, pp. 173-180. doi:0378-5955(92)90183-N

[50] S. Kurt, M. Groszer, S. E. Fisher and G. Ehret, "Modified Sound-Evoked Brainstem Potentials in Foxp2 Mutant Mice,” Brain Research, Vol. 1289, 2009, pp. 30-36. doi:j.brainres.2009.06.092

[51] M. P. Gorga, D. W. Worthington, J. K. Reiland, K. A. Beauchaine and D. E. Goldgar, "Some Comparisons between Auditory Brain Stem Response Thresholds, Latencies, and the Pure-Tone Audiogram," Ear and Hearing, Vol. 6, No. 2, 1985, pp. 105-112.

[52] T. W. Picton, A. Durieux-Smith and L. M. Moran, "Recording Auditory Brainstem Responses from Infants," International Journal of Pediatric Otorhinolaryngology, Vol. 28, No. 2-3, 1994, pp. 93-110. doi:0165-5876(94)90001-9

[53] F. A. Boettcher, J. H. Mills, J. R. Dubno and R. A. Schmiedt, "Masking of Auditory Brainstem Responses in Young and Aged Gerbils,” Hearing Research, Vol. 89, No. 1-2, 1995, pp. 1-13. doi:0378-5955(95)00116-X

[54] N. J. Ingham, S. K. Thornton, S. D. Comis and D. J. Withington, "The Auditory Brainstem Response of Aged Guinea Pigs,” Acta Otolaryngologica, Vol. 118, No. 5, 1998, pp. 673-680.

[55] T. Fowler, B. Canlon, D. Dolan and J. M. Miller, “The Effect of Noise Trauma Following Training Exposures in the Mouse," Hearing Research, Vol. 88, No. 1-2, 1995, pp. 1-13. doi:0378-5955(95)00062-9

[56] J. Popelar, J. Grecova, N. Rybalko and J. Syka, “Comparison of Noise-Induced Changes of Auditory Brainstem and Middle Latency Response Amplitudes in Rats," Hearing Research, Vol. 245, No. 1-2, 2008, pp. 82-91. doi:j.heares.2008.09.002

[57] Q. Y. Zheng, K. R. Johnson and L. C. Erway, “Assessment of Hearing in 80 Inbred Strains of Mice by ABR Threshold Analyses," Hearing Research, Vol. 130, No. 12, 1999, pp. 94-107. doi:S0378-5955(99)00003-9

[58] L. O. Trussell, "Synaptic Mechanisms for Coding Timing in Auditory Neurons,” Annual Review of Physiology, Vol. 61, 1999, pp. 477-496. doi:annurev.physiol.61.1.477

[59] R. G. Turcott, et al., “A Nonstationary Poisson Point Process Describes the Sequence of Action Potentials over Long Time Scales in Lateral-Superior-Olive Auditory Neurons,” Biological Cybernetics, Vol. 70, No. 3, 1994, pp. 209-217. doi:BF00197601

[60] J. R. Melcher and N. Y. Kiang, "Generators of the Brainstem Auditory Evoked Potential in Cat. III: Identified Cell Populations,” Hearing Research, Vol. 93, No. 1-2, 1996, 


\section{pp. 52-71. doi:0378-5955(95)00200-6}

[61] B. J. Malone, B. H. Scott and M. N. Semple, "Context-Dependent Adaptive Coding of Interaural Phase Disparity in the Auditory Cortex of Awake Macaques," Journal of Neuroscience, Vol. 22, No. 11, 2002, pp. 46254638.

[62] J. A. Hobin, K. A. Goosens and S. Maren, “Context-Dependent Neuronal Activity in the Lateral Amygdala Represents Fear Memories after Extinction," Journal of Neuroscience, Vol. 23, No. 23, 2003, pp. 8410-8416.

[63] J. R. Melcher, J. J. Guinan Jr., I. M. Knudson and N. Y. Kiang, "Generators of the Brainstem Auditory Evoked Potential in Cat. II. Correlating Lesion Sites with Waveform Changes,” Hearing Research, Vol. 93, No. 1-2, 1996, pp. 28-51. doi:0378-5955(95)00179-4

[64] R. E. Lasky, "Rate and Adaptation Effects on the Auditory Evoked Brainstem Response in Human Newborns and Adults," Hearing Research, Vol. 111, No. 1-2, 1997, pp. 165-176. doi:S0378-5955(97)00106-8

[65] Q. C. Chen and P. H. Jen, "Pulse Repetition Rate Increases the Minimum Threshold and Latency of Auditory Neurons,” Brain Research, Vol. 654, No. 1, 1994, pp. 155-158. doi:0006-8993(94)91582-2

[66] L. Ruttiger, et al., "BDNF mRNA Expression and Protein Localization are Changed in Age-Related Hearing Loss," Neurobiology of Aging, Vol. 28, No. 4, 2007, pp. 586-601. doi:j.neurobiolaging.2006.02.008

[67] M. D. Szymanski, K. R. Henry and F. O. Buchting, “Albino and Pigmented Gerbil Auditory Function: Influence of Genotype and Gentamicin,” Audiology, Vol. 33, No. 2, 1994, pp. 63-72.

[68] R. H. Fitch, S. W. Threlkeld, M. M. McClure and A. M. Peiffer, "Use of a Modified Prepulse Inhibition Paradigm to Assess Complex Auditory Discrimination in Rodents," Brain Research Bulletin, Vol. 76, No. 1-2, 2008, pp. 1-7. doi:j.brainresbull.2007.07.013

[69] J. T. Friedman, A. M. Peiffer, M. G. Clark, A. A. Benasich and R. H. Fitch, "Age and Experience-Related Improvements in Gap Detection in the Rat," Developmental Brain Research, Vol. 152, No. 2, 2004, pp. 83-91. doi:j.devbrainres.2004.06.007

[70] J. R. Ison and E. E. Krauter, “Acoustic Startle Reflexes in the Rat During Consummatory Behavior," Journal of Comparative and Physiological Psychology, Vol. 89, No. 1, 1975, pp. 39-49. doi:h0076387

[71] P. K. Pilz and H. U. Schnitzler, "Habituation and Sensitization of the Acoustic Startle Response in Rats: Amplitude, Threshold, and Latency Measures," Neurobiology of Learning and Memory, Vol. 66, No. 1, 1996, pp. 67-79. doi:nlme.1996.0044

[72] H. Schulze and H. Scheich, "Discrimination Learning of Amplitude Modulated Tones in Mongolian Gerbils," Neuroscience Letters, Vol. 261, No. 1-2, 1999, pp. 13-16.
doi:S0304-3940(98)00991-4

[73] E. A. Blakeslee, K. Hynson, R. P. Hamernik and D. Henderson, "Asymptotic Threshold Shift in Chinchillas Exposed to Impulse Noise," Journal of the Acoustical Society of America, Vol. 63, No. 3, 1978, pp. 876-882. doi:1.381767

[74] M. Brosch and C. E. Schreiner, "Time Course of Forward Masking Tuning Curves in Cat Primary Auditory Cortex,” Journal of Neurophysiology, Vol. 77, No. 2, 1997, pp. 923-943.

[75] M. B. Calford and M. N. Semple, "Monaural Inhibition in Cat Auditory Cortex,” Journal of Neurophysiology, Vol. 73, No. 5, 1995, pp. 1876-1891.

[76] S. L. Sally and J. B. Kelly, "Organization of Auditory Cortex in the Albino Rat: Sound Frequency,” Journal of Neurophysiology, Vol. 59, No. 5, 1988, pp. 1627-1638.

[77] G. Ehret, "Psychoacoustics,” In: J. F. Willott, Ed., The Auditory Psychobiology of the Mouse, Charles C. Thomas, Springfield, 1983, pp. 13-56.

[78] I. Hamann, et al., "Behavioral and Evoked-Potential Thresholds in Young and Old Mongolian Gerbils (Meriones unguiculatus)," Hearing Research, Vol. 171, No. 1-2, 2002, pp. 82-95. doi:S0378-5955(02)00454-9

[79] O. Bar-Yosef, Y. Rotman and I. Nelken, "Responses of Neurons in Cat Primary Auditory Cortex to Bird Chirps: Effects of Temporal and Spectral Context," Journal of Neuroscience, Vol. 22, No. 19, 2002, pp. 8619-8632.

[80] N. Schmajuk, "Brain-Behaviour Relationships in Latent Inhibition: A Computational Model,” Neuroscience \& Biobehavioral Reviews, Vol. 29, No. 6, 2005, pp. 1001-1020. doi:j.neubiorev.2005.02.005

[81] P. K. Pilz, J. Ostwald, A. Kreiter and H. U. Schnitzler, "Effect of the Middle Ear Reflex on Sound Transmission to the Inner Ear of Rat,” Hearing Research, Vol. 105, No. 1-2, 1997, pp. 171-182. doi:S0378-5955(96)00206-7

[82] L. G. Reijmers and B. W. Peeters, "Effects of Acoustic Prepulses on the Startle Reflex in Rats: A Parametric Analysis,” Brain Research, Vol. 667, No. 1, 1994, pp. 144-150. doi:0006-8993(94)91727-2

[83] G. S. Borszcz, J. Cranney and R. N. Leaton, "Influence of Long-Term Sensitization on Long-Term Habituation of the Acoustic Startle Response in Rats: Central Gray Lesions, Preexposure, and Extinction," Journal of Experimental Psychology: Animal Behavior Processes, Vol. 15, No. 1, 1989, pp. 54-64.

[84] C. C. Chabot and D. H. Taylor, "Circadian Modulation of the Rat Acoustic Startle Response,” Behavioral Neuroscience, Vol. 106, No. 5, 1992, pp. 846-852. doi:0735-7044.106.5.846

[85] B. H. Gaese, M. Nowotny and P. K. Pilz, "Acoustic Startle and Prepulse Inhibition in the Mongolian Gerbil," Physiology \& Behavior, Vol. 98, No. 4, 2009, pp. 460466. doi:j.physbeh.2009.07.014 